Prepared for the U.S. Department of Energy under Contract DE-AC05-76RL01830

\title{
Measurement of the Tracer Gradient and Sampling System Bias of the Hot Fuel Examination Facility Stack Air Monitoring System
}

\section{JA Glissmeyer \\ JE Flaherty}

July 2011

\section{Pacific Northwest}

NATIONAL LABORATORY

Proudly Operated by Battelle Since 1965 


\title{
DISCLAIMER
}

This report was prepared as an account of work sponsored by an agency of the United States Government. Neither the United States Government nor any agency thereof, nor Battelle Memorial Institute, nor any of their employees, makes any warranty, express or implied, or assumes any legal liability or responsibility for the accuracy, completeness, or usefulness of any information, apparatus, product, or process disclosed, or represents that its use would not infringe privately owned rights. Reference herein to any specific commercial product, process, or service by trade name, trademark, manufacturer, or otherwise does not necessarily constitute or imply its endorsement, recommendation, or favoring by the United States Government or any agency thereof, or Battelle Memorial Institute. The views and opinions of authors expressed herein do not necessarily state or reflect those of the United States Government or any agency thereof.

\author{
PACIFIC NORTHWEST NATIONAL LABORATORY \\ operated by \\ BATTELLE \\ for the \\ UNITED STATES DEPARTMENT OF ENERGY \\ under Contract DE-ACO5-76RL01830
}

Printed in the United States of America
Available to DOE and DOE contractors from the Office of Scientific and Technical Information,
P.O. Box 62, Oak Ridge, TN 37831-0062;
ph: (865) 576-8401
fax: (865) 5765728
email: reports@adonis.osti.gov

\author{
Available to the public from the National Technical Information Service, \\ U.S. Department of Commerce, 5285 Port Royal Rd., Springfield, VA 22161 \\ ph: (800) 553-6847 \\ fax: (703) 605-6900 \\ email: orders@nits.fedworld.gov \\ online ordering: http://www.ntis.gov/ordering.htm
}


PNNL-20497

RPT-STMON-008

\title{
Measurement of the Tracer Gradient and Sampling System Bias of the Hot Fuel Examination Facility Stack Air Monitoring System
}

\author{
J. A. Glissmeyer \\ J. E. Flaherty
}

July 2011

This document was prepared for Battelle Energy Alliance, LLC as part of a Memorandum of Purchase Order (No. 00097184). The testing described in this document was further guided by the Tests of Tracer Gradient and Sampling System Bias in the Hot Fuel Examination Facility Air Exhaust System Test Plan (TP-STMON-022).

Pacific Northwest National Laboratory

Richland, Washington 99352 



\section{Completeness of Testing}

This report describes the results of work and testing specified by test plan TP-STMON022. The work and any associated testing followed the quality assurance requirements outlined in the test specification/plan. The descriptions provided in this test report are an accurate account of both the conduct of the work and the data collected. Test plan results are reported. Also reported are any unusual or anomalous occurrences that are different from expected results. The test results and this report have been reviewed and verified.

\section{Approved:}

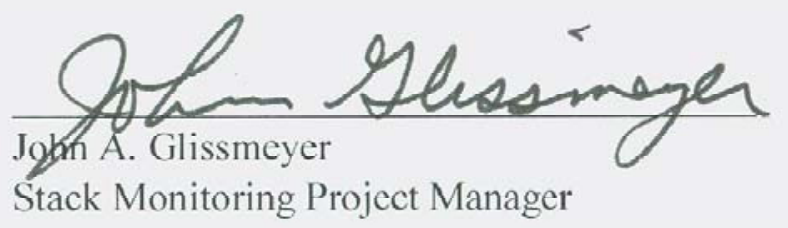

_June 14, 2011

Date 



\section{Acronyms}

$\begin{array}{ll}\text { ANSI } & \text { American National Standards Institute } \\ \text { ASME } & \text { American Society of Mechanical Engineers } \\ \text { BEA } & \text { Battelle Energy Alliance, LLC } \\ \text { BT } & \text { Bias test } \\ \text { CFR } & \text { Code of Federal Regulations } \\ \text { COV } & \text { coefficient of variance } \\ \text { DOE } & \text { U.S. Department of Energy } \\ \text { GT } & \text { Gradient test } \\ \text { HDI } & \text { "How Do I...?” } \\ \text { HFEF } & \text { Hot Fuel Examination Facility } \\ \text { HPS } & \text { Health Physics Society } \\ \text { INL } & \text { Idaho National Laboratory } \\ \text { MPO } & \text { Memorandum of Purchase Order } \\ \text { PNNL } & \text { Pacific Northwest National Laboratory } \\ \text { pPm } & \text { parts per million (by volume) } \\ \text { QA } & \text { quality assurance } \\ \text { SF } 6 & \text { sulfur hexafluoride } \\ \text { SOW } & \text { statement of work } \\ \text { STMON } & \text { Stack Monitoring Project } \\ & \end{array}$





\section{Acknowledgments}

This work was conducted under a Memorandum of Purchase Order issued by Battelle Energy Alliance, LLC (BEA) to provide funding to Pacific Northwest National Laboratory (PNNL). PNNL is operated for the U.S. Department of Energy by Battelle under Contract DE-AC05-76RL01830.

Preparation and execution of this study involved a number of staff from both PNNL and BEA and its contractors. We would like to particularly acknowledge the support of our quality engineer, Kirsten Meier, our safety and health representative Renee Gray and administrative support from Andrea Boehler, Mona Champion, and Chrissy Charron. We would also like to acknowledge the technical reviews conducted by Rosanne Aaberg, Ernest Antonio, Carmina Arimescu, and Matthew Barnett. Meredith Willingham provided editorial support for this report. The team of support staff at BEA was also integral to the successful completion of the work conducted at the Materials and Fuel Complex (MFC). We especially appreciate the efforts of Micheal Bybee and Tim Solle for arranging training, radiological worker and radiation protection support. 


\section{Table of Contents}

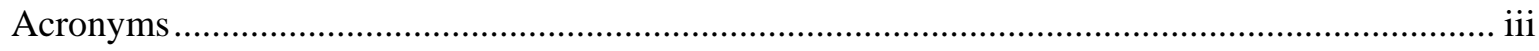

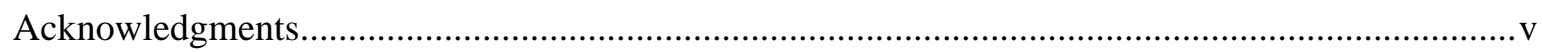

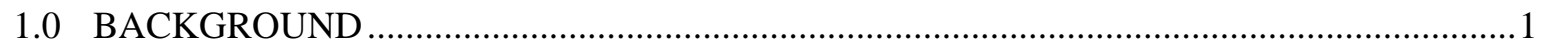

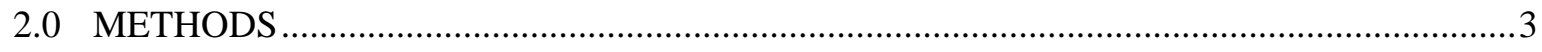

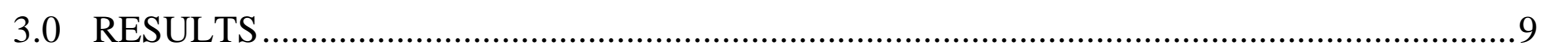

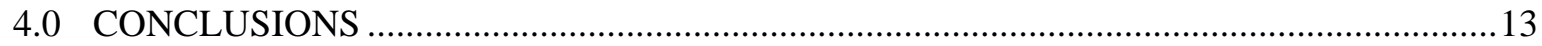

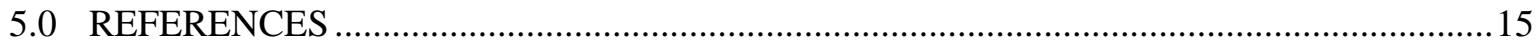

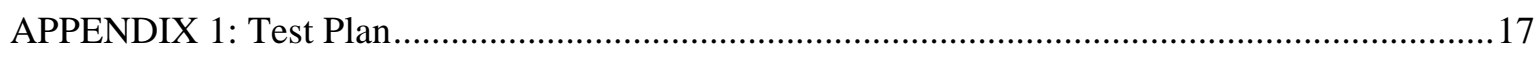

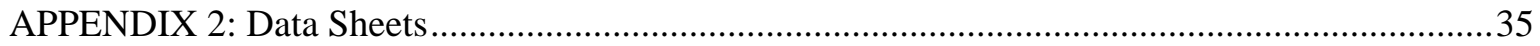

\section{Figures}

Figure 1. Gradient test sampling locations on the HFEF stack. (a) Four north ports, numbered 1 through 4 from right to left. (b) West port with Plexiglass flange cover and sampling probe

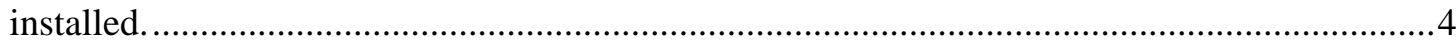

Figure 2. Bias test sampling location on the HFEF stack and on the stack sampling tubing. (a) Stack sampling tubing measurement location at the "big tee." (b) The interior of the HFEF stack showing the shrouded and test probe as observed through the West Port Plexiglas flange cover. 5

Figure 3. Tracer gas was injected into the process air via the 1" port at the bottom of the stack......6

Figure 4. Equipment used for the gaseous tracer sampling. The small air pump (right) draws air through the sample line such that the photoacoustic analyzer (center) can draw air from the line through the tee.

Figure 5. The shrouded probe position as observed at the start of testing activities. The tip was approximately 7 inches further east than plumb.

Figure 6. Plan view of $\mathrm{SF}_{6}$ concentrations within the HFEF stack measured during GT-3N (4 x 5 grid of circular markers) and GT-3W (single diamond marker). The markers are colored according to the concentration as well as labeled with the concentration value. Note that the measurement at GT-3W is 30 inches higher in elevation compared to the measurements made for GT-3N.

Figure 7. Plan view of $\mathrm{SF}_{6}$ concentration contours in ppm within the HFEF stack measured during (a) GT-1 and (b) GT-3N. (Note that the line colors are different from the marker colors in Figure 6.) The two diamond markers represent the location of the shrouded probe tip when the probe was found non-plumb, and when it was corrected to plumb. 


\section{Tables}

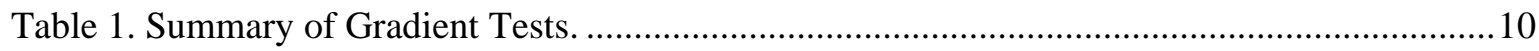

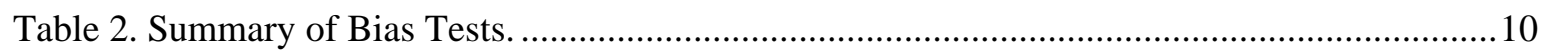





\subsection{BACKGROUND}

The objective of additional testing conducted at the Hot Fuel Examination Facility (HFEF) during April 2011 was to follow up on recommendations that resulted from previous stack sampling assessments made during July 2010 and documented in Glissmeyer and Flaherty (2010). The testing described in this report aimed to determine if a stack sampling bias existed and better quantify the concentration gradient within the HFEF stack in further detail to provide a basis for remedial actions on the air sampling system. These stack testing activities were conducted per SOW-8469, Rev 1 and Memorandum Purchase Order No. 00097184, Amendment No. 4 between Battelle Energy Alliance, LLC and Pacific Northwest National Laboratory (PNNL). 



\subsection{METHODS}

The testing described in this document was guided by the test plan titled Tests of Tracer Gradient and Sampling System Bias in the Hot Fuel Examination Facility Air Exhaust System (TP-STMON-022). The Test Instructions described the specific steps followed to complete the tests. The Operating Procedure referenced in the Test Instructions contains some general information about how to conduct these types of tests. The test plan and quality-assured data sheets are included as appendices to this report.

Two main types of tests were conducted at HFEF during April 2011:

1. Gradient Tests

2. Bias Tests

Gradient tests measured the concentration of a tracer gas at various points at a fixed elevation in the stack. The aim of the gradient tests was to document the spatial variation of the concentration within the HFEF stack. Although a single point shrouded probe has been installed in this system per the ANSI/HPS N13.1-1999 standard, previous testing showed that the stack is not well-mixed. Therefore, as a mitigation step, measurements to establish the difference between the stack mean concentration and the single-point shrouded probe sampling concentration have been conducted.

Two types of gradient tests were conducted on the HFEF stack. Gradient tests from the north ports measured the concentration on a 4 x 5 two-dimensional grid to estimate the mean concentration in the stack. Gradient tests from the west port measured the concentration on a 20-point one-dimensional grid to document the concentration gradient across the width of the stack. Figure 1 shows the sampling ports used for the gradient tests.

Bias tests measured the concentration of a tracer gas in the stack concurrently with measurements of the tracer concentration as delivered through the stack sampling system. The aim of the bias tests was to document the tracer concentration near the inlet of the shrouded probe in the stack relative to the tracer concentration as measured through the stack sampling system to explore the suspected sampling bias resulting from the July 2010 testing. Figure 2 shows the two sampling locations for the bias tests. 


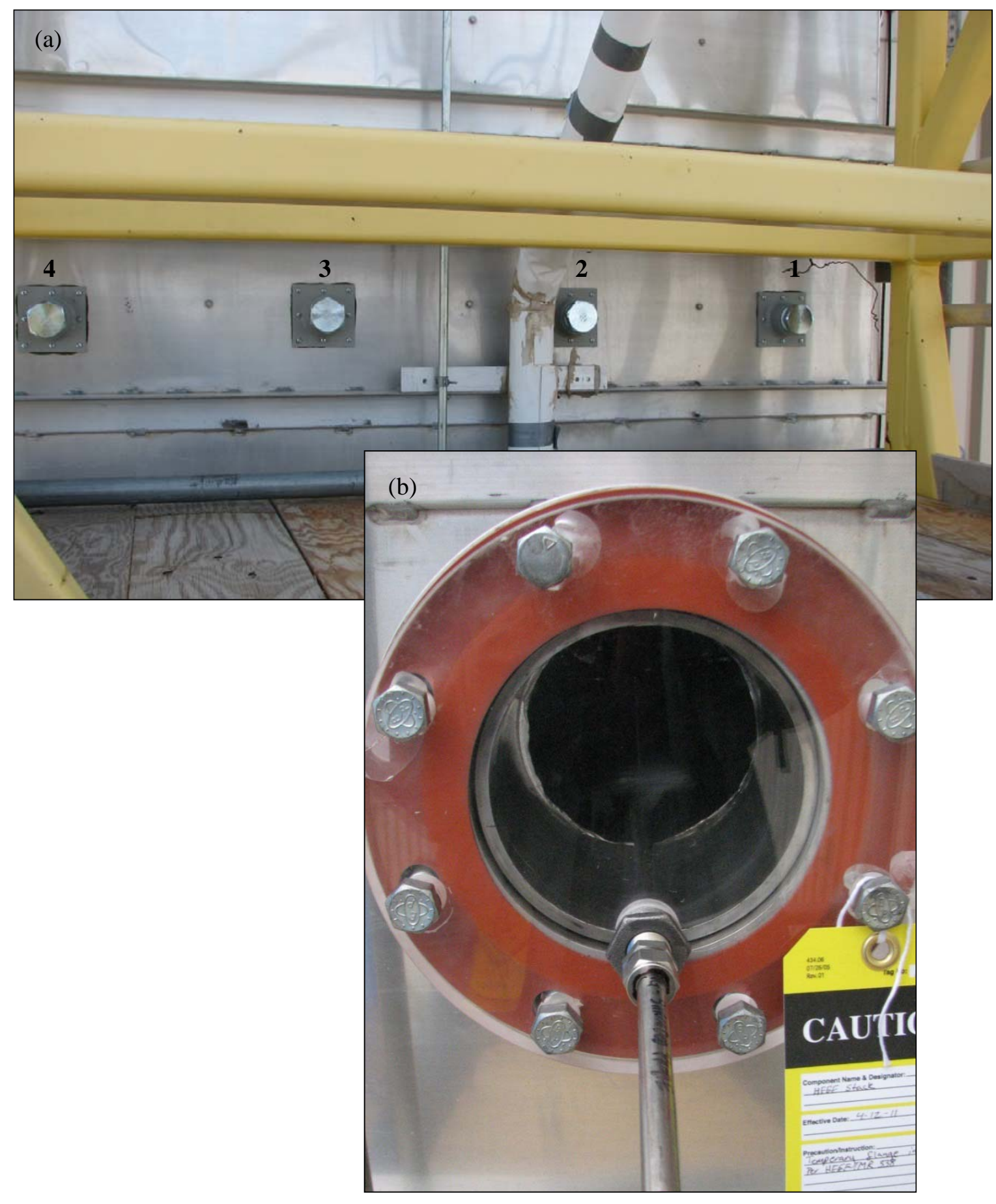

Figure 1. Gradient test sampling locations on the HFEF stack. (a) Four north ports, numbered 1 through 4 from right to left. (b) West port with Plexiglass flange cover and sampling probe installed. 


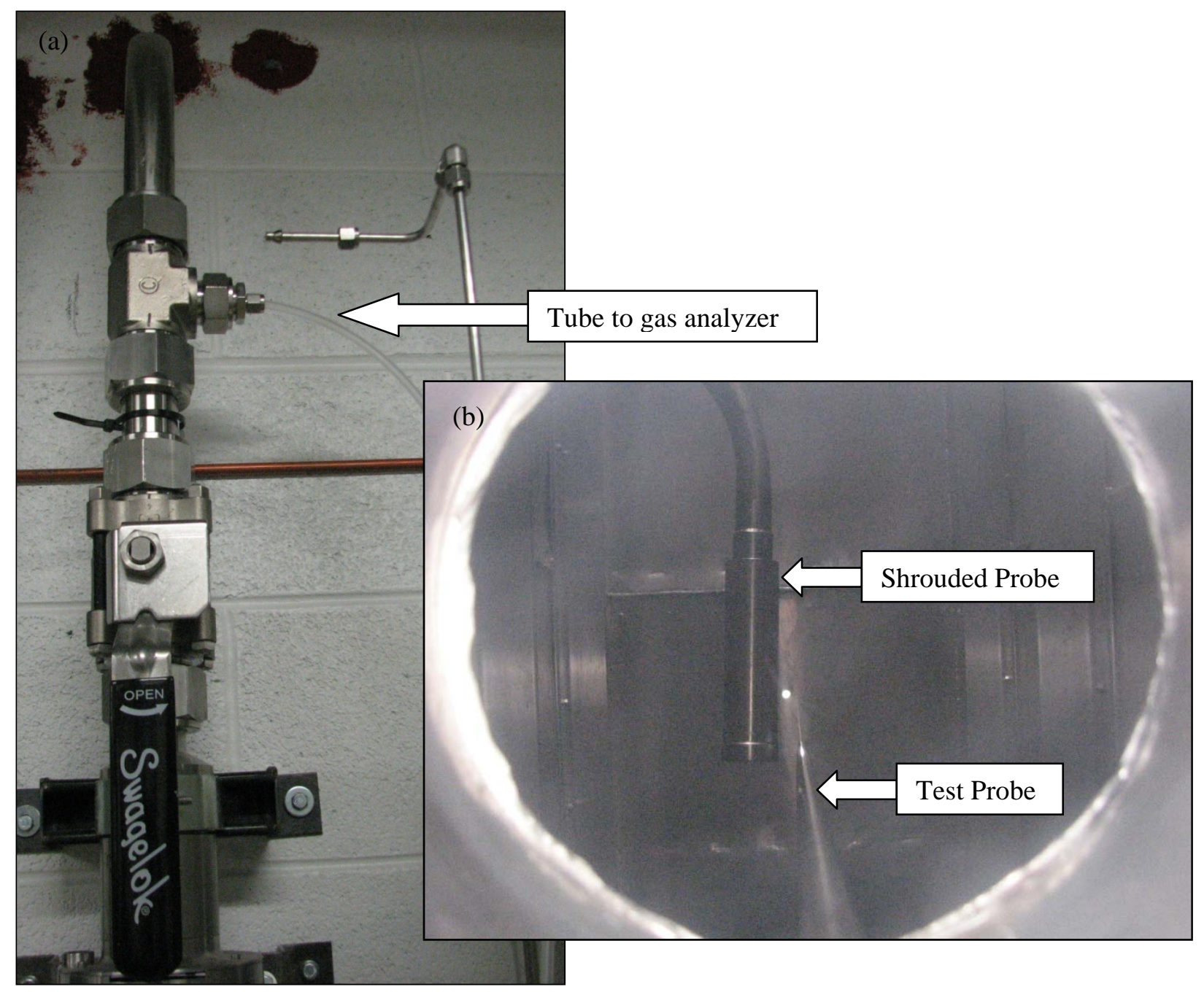

Figure 2. Bias test sampling location on the HFEF stack and on the stack sampling tubing. (a) Stack sampling tubing measurement location at the "big tee." (b) The interior of the HFEF stack showing the shrouded and test probe as observed through the West Port Plexiglas flange cover.

Sulfur hexafluoride $\left(\mathrm{SF}_{6}\right)$ tracer gas was used for all of the tests. Pure $\mathrm{SF}_{6}$ gas was injected at the bottom of the stack into the exhaust air from the process compartments of the building. (See Figure 3.) The injection flowrate was controlled with a mass-flow controller. Tracer gas concentration was measured with photoacoustic gas analyzers (Brüel \& Kjær, Model 1302, Ballerup, Denmark). A simple probe was used to extract the sample and deliver it to the gas analyzer, while a small pump drew air from within the stack or sampling tubing. The gas analyzer collected air samples from a tee in the main sample line. Figure 4 shows the equipment set-up (gas analyzer, tee in the sample line, and small pump) used for collecting air samples. 


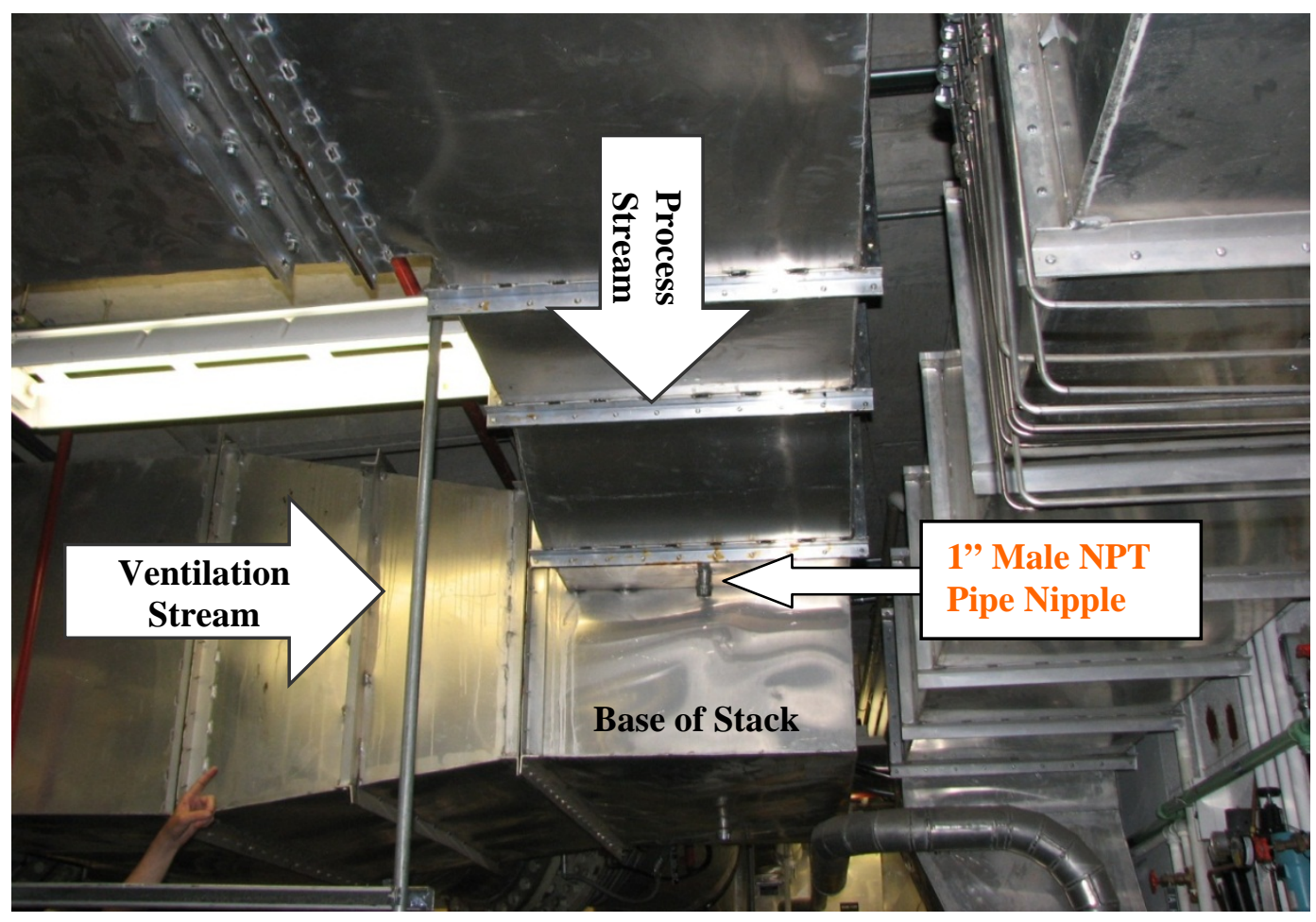

Figure 3. Tracer gas was injected into the process air via the 1” port at the bottom of the stack.

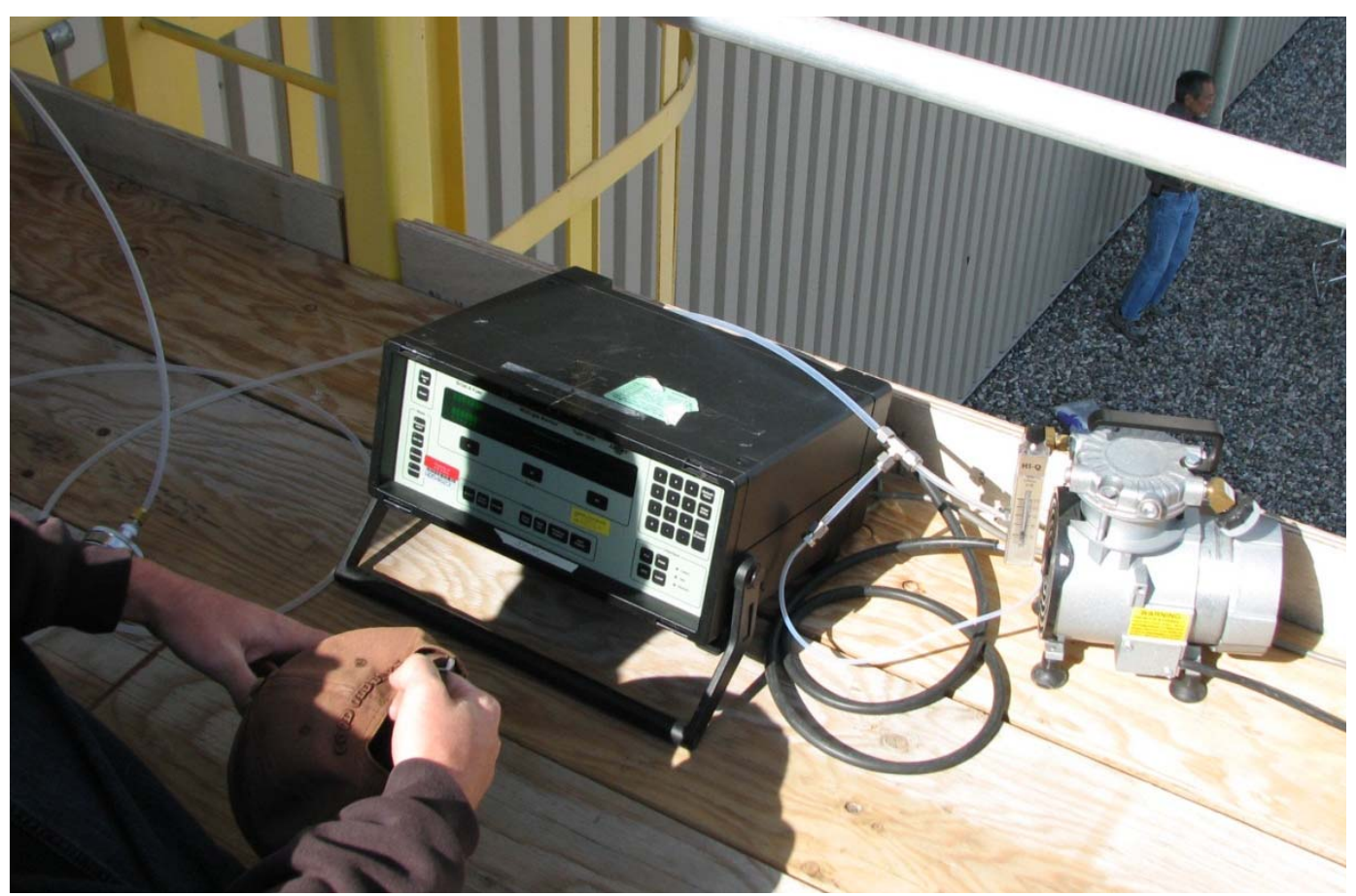

Figure 4. Equipment used for the gaseous tracer sampling. The small air pump (right) draws air through the sample line such that the photoacoustic analyzer (center) can draw air from the line through the tee. 


\subsection{Quality Assurance}

The PNNL Quality Assurance (QA) Program is based upon the requirements defined in the U.S. Department of Energy Order 414.1C, Quality Assurance, and 10 CFR 830, Energy/Nuclear Safety Management, and Subpart A-Quality Assurance Requirements (a.k.a., the Quality Rule). PNNL has chosen to implement the following consensus standards in a graded approach:

- ASME NQA-1-2000, Quality Assurance Requirements for Nuclear Facility Applications, Part 1, Requirements for Quality Assurance Programs for Nuclear Facilities.

- ASME NQA-1-2000, Part II, Subpart 2.7, Quality Assurance Requirements for Computer Software for Nuclear Facility Applications.

- ASME NQA-1-2000, Part IV, Subpart 4.2, Graded Approach Application of Quality Assurance Requirements for Research and Development.

The procedures necessary to implement the requirements are documented through PNNL's "How Do I...?” $\left(\mathrm{HDI}^{1}\right)$.

The Stack Monitoring Project (STMON) implements an NQA-1-2000 Quality Assurance Program, graded on the approach presented in NQA-1-2000, Part IV, Subpart 4.2. The STMON Quality Assurance Manual (QA-STMON-0002) describes the technology life cycle stages under the STMON Quality Assurance Plan (QA-STMON-0001). The technology life cycle includes the progression of technology development, commercialization, and retirement in process phases of basic and applied research and development (R\&D), engineering and production and operation until process completion. The life cycle is characterized by flexible and informal quality assurance activities in basic research, which becomes more structured and formalized through the applied R\&D stages.

The work described in this report has been completed under the QA Technology level of Development Work. STMON addresses internal verification and validation activities by conducting an Independent Technical Review of the final data report in accordance with STMON's procedure QASTMON-601, Document Preparation and Change. This review verifies that the reported results are traceable, that inferences and conclusions are soundly based, and the reported work satisfies the Test Plan objectives.

${ }^{1}$ System for managing the delivery of laboratory-level policies, requirements, and procedures. 



\subsection{RESULTS}

During April 2011, staff from PNNL conducted gradient tests (GT) and bias tests (BT) at the Hot Fuel Examination Facility exhaust stack. A summary of these tests is included in Table 1 and Table 2. The tests are listed in the table in the order in which each test was conducted. GT-1 and GT-2 were conducted first, followed by the BT series, and GT-3N and GT-3W were conducted simultaneously following the BT's.

As established during the July 2010 HFEF stack testing activities, the gaseous emissions from the process ventilation stream is not well-mixed with the building ventilation stream. Test GT-1, which measured concentrations on a $4 \times 5$ grid of points in the exhaust stream, confirmed that the stack mixing conditions are similar to the previous tests. The coefficient of variance $\left(\mathrm{COV}^{2}\right)$ was $120 \%$ during GT-1. GT-2 examined the concentration gradient as the sampling probe was moved along a 20-point, onedimensional grid from the west wall to the east wall. The COV was 97\% during GT-2.

Several bias tests were conducted to determine whether the concentration (measured in parts per million by volume [ppm]) within the stack was accurately sampled by the stack sampling system. Tests were initially conducted with the sampling probe near the shrouded probe. The shrouded probe was not plumb at the start of the tests (see Figure 5), and the probe tip was slightly north of the stack centerline during these tests. Later tests placed the sampling probe directly underneath (and in contact with) the shrouded probe. Several bias tests were conducted, and each resulted in differing concentrations between the two measurement locations.

During the course of bias testing, the impact of sampling line pressures on concentrations was observed. As a result, the final bias test (BT-3b) was conducted using Tedlar® bags (SKC model 232-05, Fullerton, CA) instead of the in-line gas analyzer setup. When the contents of the Tedlar ${ }^{\circledR}$ bags were delivered to the gas analyzer, the concentrations from the two sampling locations matched very well (5.73 vs $5.76 \mathrm{ppm})$.

Finally, a gradient test was conducted on the 4 x 5 grid (GT-3N) while simultaneously measuring tracer concentration at a single point directly underneath the shrouded probe (GT-3W). Test runs GT-3N and GT-3W determined the stack mean concentration as well as the concentration measured at the entrance to the shrouded probe. Figure 6 shows the mean concentration at each point from these runs; GT-3N is shown by the circular markers while GT-3W is shown by the single diamond marker.

As mentioned previously, the shrouded probe was not plumb at the start of testing activities. To estimate the concentration measured through the shrouded probe relative to the stack mean concentration, the position of the plumb and non-plumb probe in the stack has been plotted on contour plots of the stack concentration in Figure 7. Several tests measured the concentration at the plumb and non-plumb locations; however, measurements made during separate tests cannot be reliably compared, given the pressure effects observed during the bias tests. Therefore, estimates based on contour plots are the only

\footnotetext{
${ }^{2} \mathrm{COV}$ is equivalent to the relative standard deviation. It is calculated as the standard deviation of the concentration measured for each point divided by the mean for all the points, expressed as a percentage. The value should be less than $20 \%$ to be considered well mixed. Also, the concentration at any of the measurement points should not differ from the mean by more than $30 \%$.
} 
internally-consistent estimate that can be produced. There are some slight differences in the shape of the contour lines for higher concentrations between GT-1 and GT-3N, which result in some differences in the concentrations at the non-plumb and plumb positions relative to the mean. For GT-1, the approximate concentration at the non-plumb position is $1.25 \mathrm{ppm}$, compared with $2.00 \mathrm{ppm}$ at the plumb position, while the mean was $1.49 \mathrm{ppm}$. The approximate concentration at the non-plumb position is $1.40 \mathrm{ppm}$ for GT-3N compared with $2.20 \mathrm{ppm}$ at the plumb position. The stack mean concentration for GT-3N was $1.94 \mathrm{ppm}$. Therefore, the non-plumb concentration was about $15 \%$ and $30 \%$ lower than the mean for GT-1 and GT-3N, respectively, while the plumb concentration was about $30 \%$ and $15 \%$ higher than the mean for the two cases.

Table 1. Summary of Gradient Tests.

\begin{tabular}{|c|l|c|c|}
\hline Test & Description & $\begin{array}{c}\text { Mean Stack } \\
\text { (ppm) }\end{array}$ & COV (\%) \\
\hline GT-1 & 20-point, 4 x 5 grid through North ports & 1.49 & 120.5 \\
\hline GT-2 & 20-point, linear grid through West Port & 0.58 & 96.5 \\
\hline GT-3N & 20-point, 4 x 5 grid through North ports & 1.94 & 112.0 \\
\hline GT-3W & $\begin{array}{l}\text { Single point directly underneath shrouded probe during } \\
\text { GT-3N }\end{array}$ & 3.01 & 6.5 \\
\hline
\end{tabular}

Table 2. Summary of Bias Tests.

\begin{tabular}{|c|c|c|c|}
\hline Test & Description & $\begin{array}{c}\text { Mean Stack } \\
\text { (ppm) }\end{array}$ & $\begin{array}{c}\text { Mean } \\
\text { Sample } \\
\text { Line (ppm) } \\
\end{array}$ \\
\hline BT-1 & $\begin{array}{l}\text { Stack: Same depth as shrouded probe, laterally separated. } \\
\text { Shrouded probe is not plumb. } \\
\text { Second Floor: "Big Tee” upstream of HOV-004 }\end{array}$ & 0.417 & 0.0061 \\
\hline BT-2a & $\begin{array}{l}\text { Stack: Same depth as shrouded probe, laterally separated. } \\
\text { Shrouded probe is plumb. } \\
\text { Second Floor: "Big Tee" upstream of HOV-004 }\end{array}$ & 1.03 & 0.44 \\
\hline BT-2b & $\begin{array}{l}\text { Stack: Directly underneath shrouded probe. } \\
\text { Shrouded probe is plumb. } \\
\text { Second Floor: "Big Tee” upstream of HOV-004 } \\
\text { In-Line filters for gas analyzers are removed. }\end{array}$ & 1.53 & 0.99 \\
\hline ВТ-За & $\begin{array}{l}\text { Stack: Directly underneath shrouded probe. } \\
\text { Shrouded probe is plumb. } \\
\text { Second Floor: "Big Tee” upstream of HOV-004. } \\
\text { In-Line filters for gas analyzers are removed. } \\
\text { HOV-004 is closed. }\end{array}$ & 3.00 & 0.95 \\
\hline BT-3b & $\begin{array}{l}\text { Stack: Directly underneath shrouded probe. } \\
\text { Shrouded probe is plumb. } \\
\text { Second Floor: "Big Tee" upstream of HOV-004. } \\
\text { HOV-004 is closed. } \\
\text { Sampled through Tedlar® bags. }\end{array}$ & 5.73 & 5.76 \\
\hline
\end{tabular}




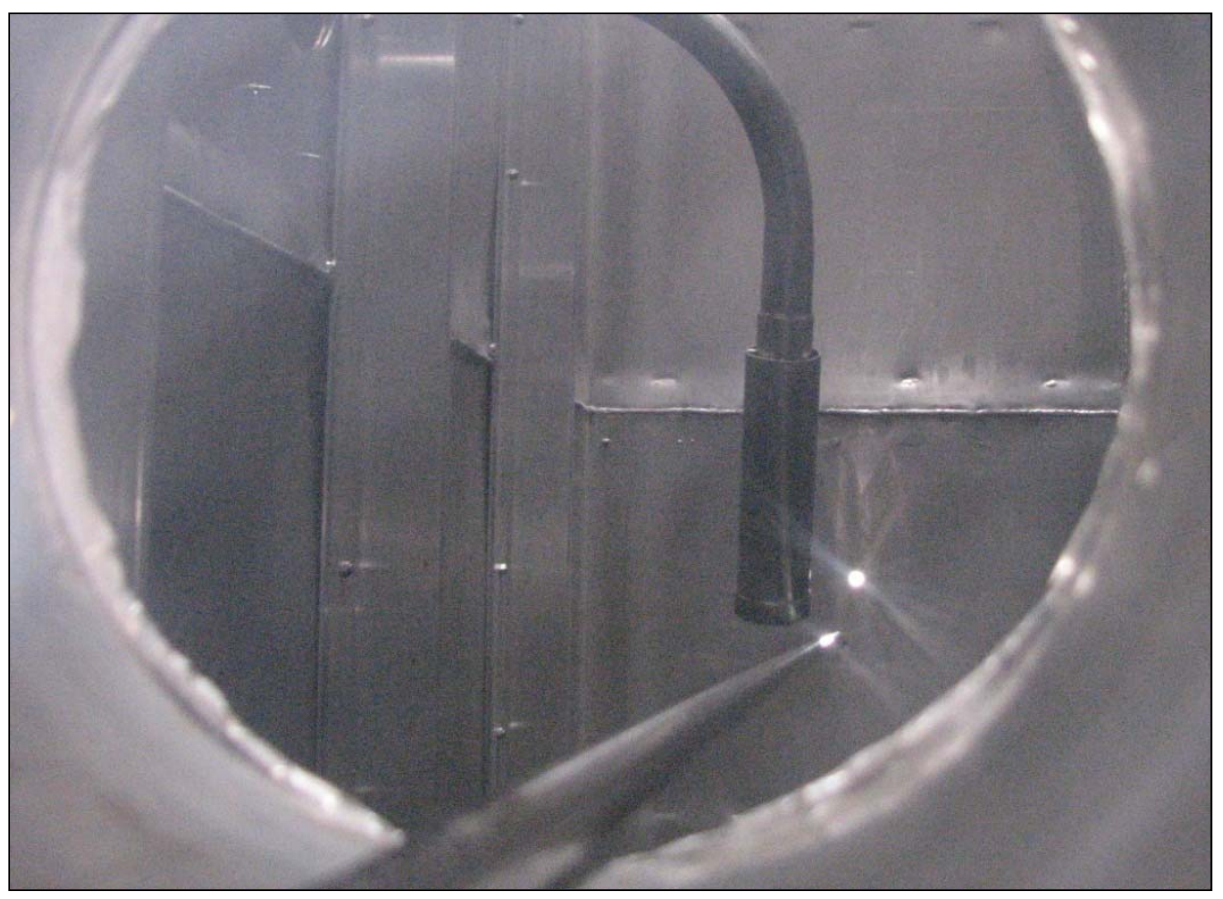

Figure 5. The shrouded probe position as observed at the start of testing activities. The tip was approximately 7 inches further east than plumb.

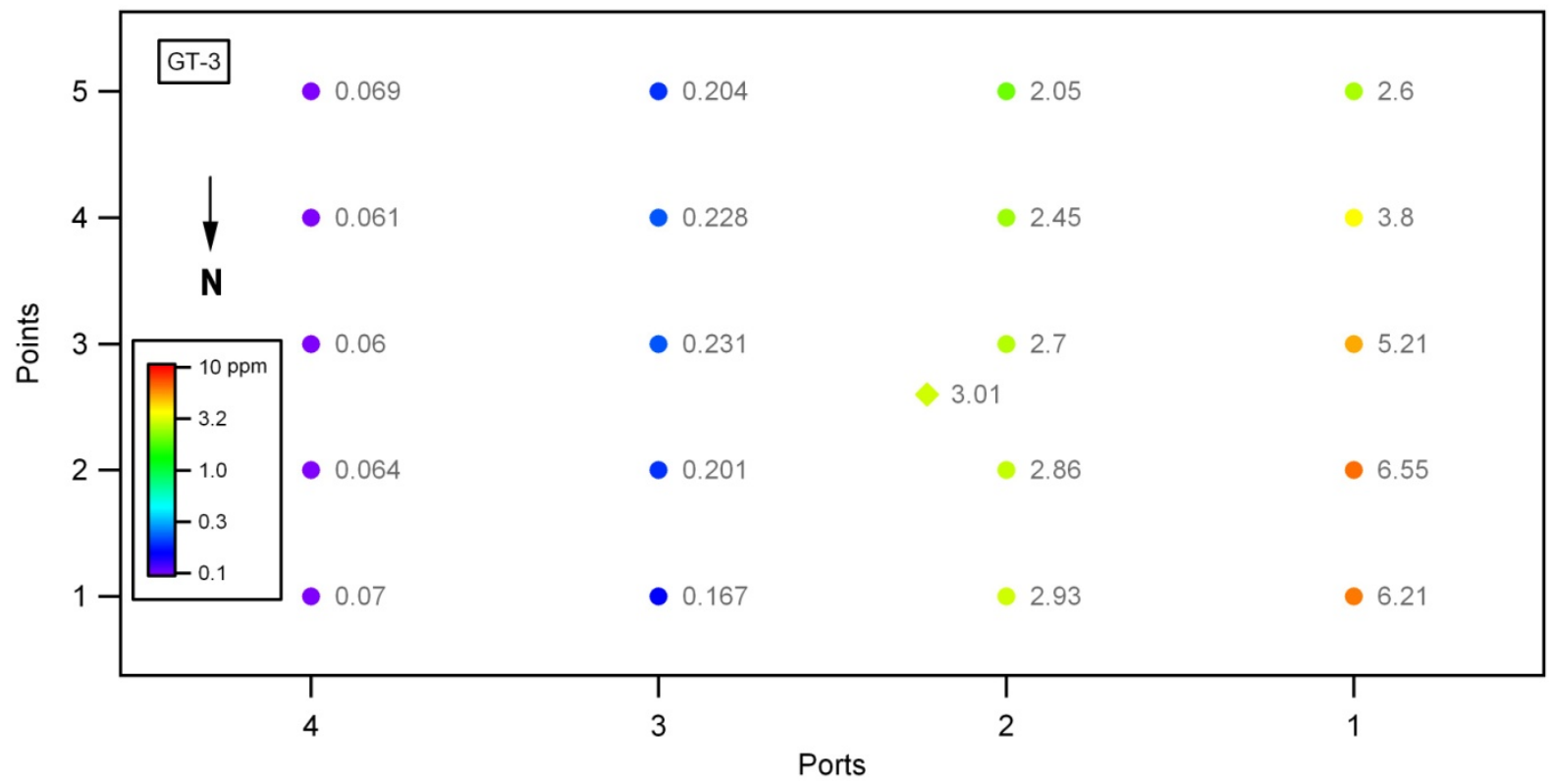

Figure 6. Plan view of $\mathrm{SF}_{6}$ concentrations within the HFEF stack measured during GT-3N ( 4 x 5 grid of circular markers) and GT-3W (single diamond marker). The markers are colored according to the concentration as well as labeled with the concentration value. Note that the measurement at GT-3W is 30 inches higher in elevation compared to the measurements made for GT-3N. 

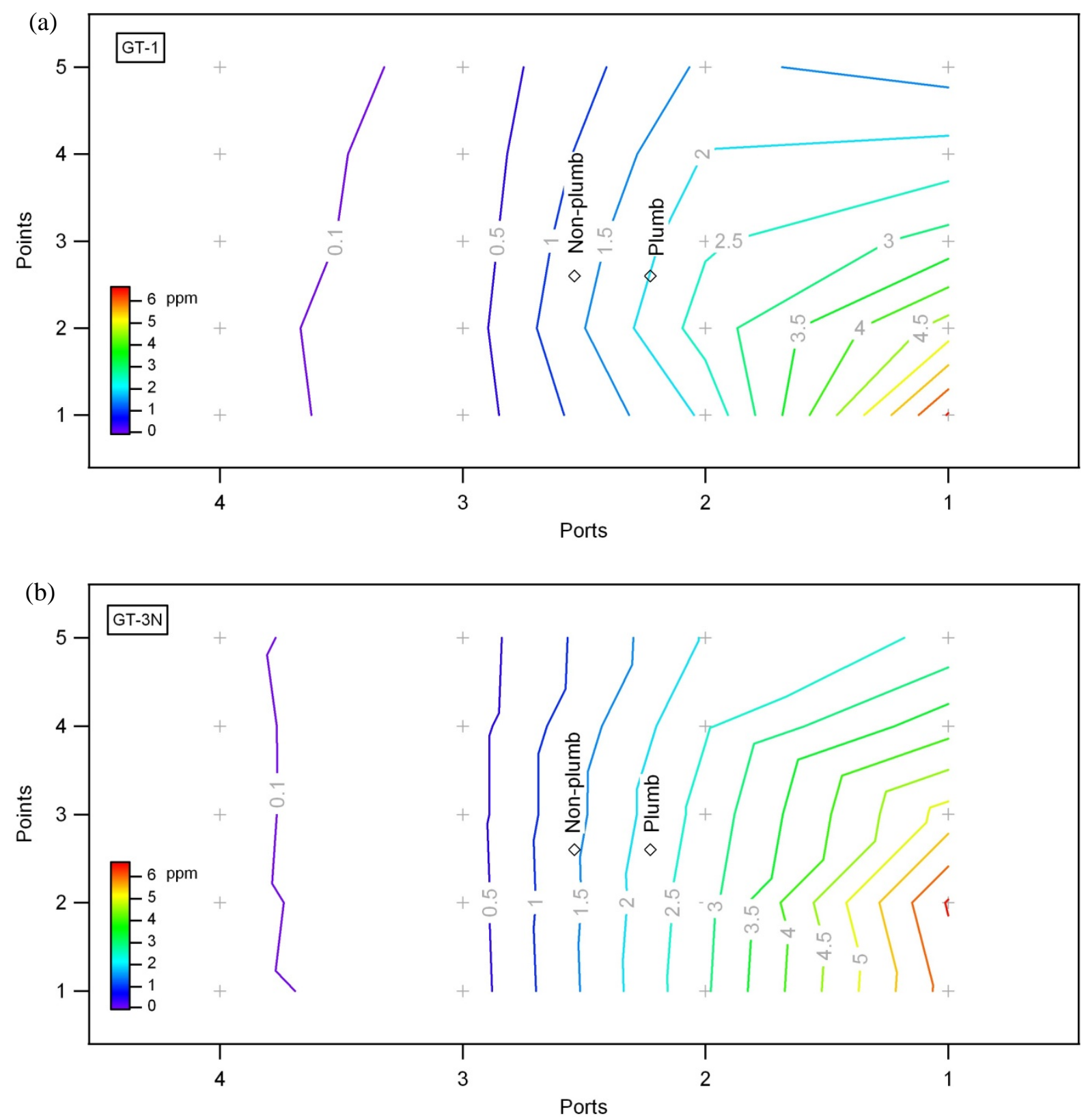

Figure 7. Plan view of $\mathrm{SF}_{6}$ concentration contours in $\mathrm{ppm}$ within the HFEF stack measured during (a) GT-1 and (b) GT-3N. (Note that the line colors are different from the marker colors in Figure 6.) The two diamond markers represent the location of the shrouded probe tip when the probe was found non-plumb, and when it was corrected to plumb. 


\subsection{CONCLUSIONS}

This report describes tracer gas gradient and bias measurements made in the exhaust air discharge of the Hot Fuel Examination Facility at Idaho National Laboratory. These measurements were conducted to follow up on measurements made at this facility during July 2010. During the July testing, measurements revealed that there is little mixing between the process and building ventilation streams. A single point shrouded probe has been installed in this system per the ANSI/HPS N13.1-1999 standard. The airstream must be well-mixed for a single point sampling probe to extract a representative sample of the entire stream. Therefore, additional measurements were made to characterize the concentrations in the stack with respect to the current probe location.

When the west port was first opened, we observed that the shrouded probe located in the HFEF stack was not pointed directly into the flow. The probe was about 20 degrees from plumb at the start of our testing activities, and was corrected during the tests. Re-positioning the shrouded probe by moving the tip approximately 7 inches toward the west wall of the stack improves the measurement through the sampling system relative to the stack mean concentration. Based on the gradient testing, we estimate that the previous probe position sampled concentrations that were about 15 to $30 \%$ lower than the stack mean concentration, while the current probe position samples concentrations that are about 15 to $30 \%$ higher than the stack mean concentration. Environmental conditions as well as changes in building ventilation conditions may impact the actual concentration gradient within the exhaust stack. Although a well-mixed stack is needed for single point sampling, the existing sampling probe configuration at HFEF extracts a conservative sample of the process air effluent. Particle line-loss and non-process effluent sampling were not addressed in these tests.

The PNNL-provided sampling system utilized for these measurements has some previouslyunidentified pressure effects that impact the instrument analysis for $\mathrm{SF}_{6}$ concentration. The suspected bias between the stack concentration and the sampling system concentration resulting from the July 2010 tests was a consequence of this pressure effect, and was not a true bias in the system. For typical tracer uniformity testing applications, where only the relative concentration is needed, the systematic error in concentration due to pressure effects does not impact the mixing results. However, absolute concentration values are not reliable between measurements made under different pressure conditions. Until the effects of pressure on the gas analyzer are fully understood and quantified, Tedlar ${ }^{\circledR}$ bags should be used when the absolute (vs relative) concentration of a tracer is necessary. 



\subsection{REFERENCES}

10 CFR 830, Subpart A. “Quality Assurance Requirements.” Code of Federal Regulations, U.S. Department of Energy.

American Society of Mechanical Engineers (ASME). 2001. Quality Assurance Requirements for Nuclear Facility Applications. NQA-1-2000, New York, NY.

ANSI/HPS N13.1-1999, Sampling and Monitoring Releases of Airborne Radioactive Substances from the Stack and Ducts of Nuclear Facilities. Health Physics Society, McLean, VA 22101.

Glissmeyer, JA, and JE Flaherty, 2010. Assessment of the Idaho National Laboratory Hot Fuel Examination Facility Stack Monitoring Site for Compliance with ANSI/HPS N13.1-1999, PNNL19659, RPT-STMON-007, Pacific Northwest National Laboratory, Richland, WA 99352.

Pacific Northwest National Laboratory (PNNL). 2010a. Stack Monitoring Project Quality Assurance Manual. QA-STMON-0002, Rev 0.0. Richland, WA.

Pacific Northwest National Laboratory (PNNL). 2010b. Stack Monitoring Project Quality Assurance Plan. QA-STMON-0001, Rev 0.0. Richland, WA.

U.S. Department of Energy. 2005. DOE O414.1C. “Quality Assurance.” Washington, D.C. 



\section{APPENDIX 1: Test Plan}





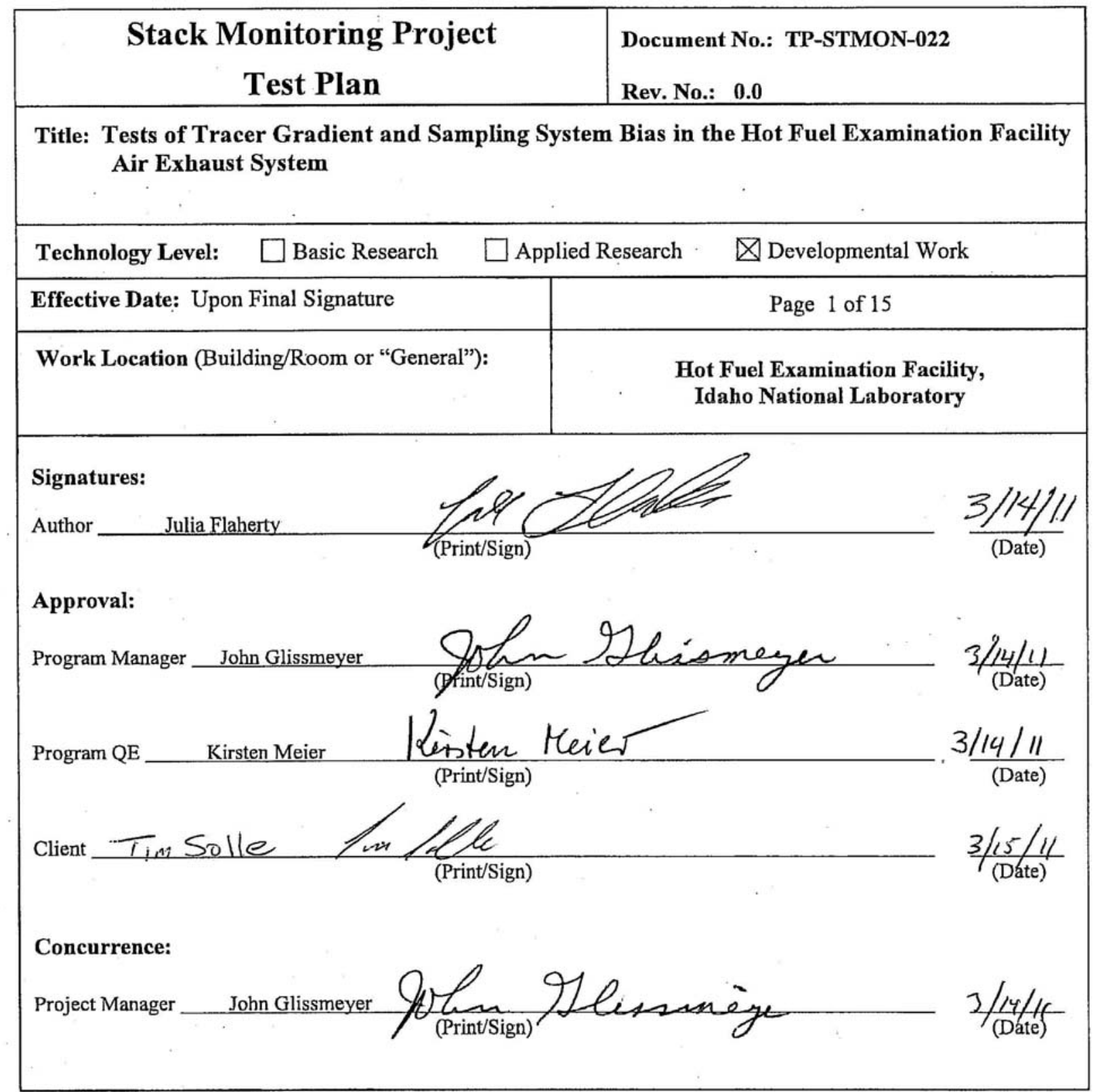


REVISION HISTORY

\begin{tabular}{|c|c|l|l|}
\hline $\begin{array}{c}\text { Revision } \\
\text { Number }\end{array}$ & $\begin{array}{c}\text { Interim } \\
\text { Change No. }\end{array}$ & Effective Date & Description of Change \\
\hline 0 & 0 & $\begin{array}{l}\text { Upon Final } \\
\text { Signature }\end{array}$ & Initial issue. \\
\hline & & & \\
\hline & & & \\
\hline & & & \\
\hline & & & \\
\hline & & & \\
\hline & & & \\
\hline
\end{tabular}




\section{$\underline{\text { Definitions/Acronyms }}$}

ANSI American National Standards Institute

ASME American Society of Mechanical Engineers

CFR Code of Federal Regulations

DOE U.S. Department of Energy

HPS Health Physics Society

M\&TE measuring and test equipment

NQA Nuclear Quality Assurance

PNNL Pacific Northwest National Laboratory

QA quality assurance

QAP quality assurance plan

R\&D research and development

TRIM PNNL'S electronic Total Records Information Management system

STMON Stack Monitoring Project 


\section{Table of Contents}

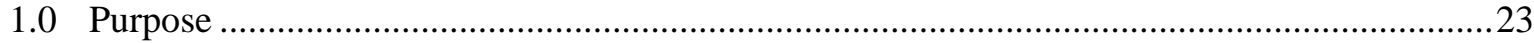

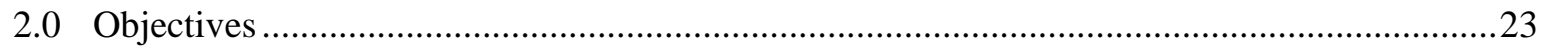

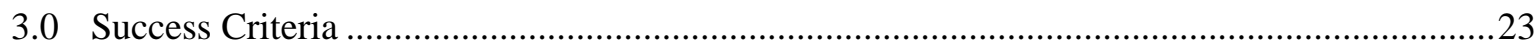

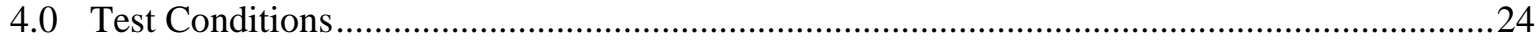

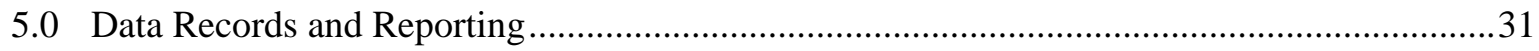

6.0 Application of Quality Assurance Requirements ...............................................................31

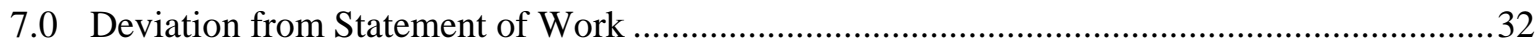

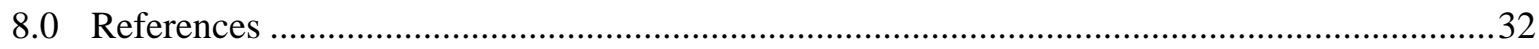

\section{Figures}

Figure 1 Tracer injection locations in the process duct in Room 209........................................................ 25

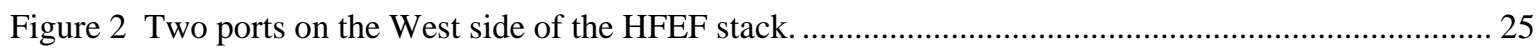

Figure 3 Preliminary sampling grid through the four ports on the North side of the HFEF stack and through

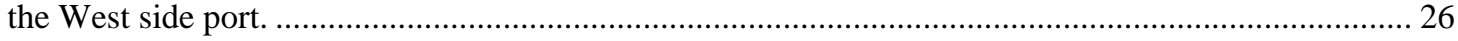

Figure 4 Sampling system tracer measurement locations in hall outside Room 209.................................. 26

Figure 5 Plan view diagram of the HFEF air exhaust system.................................................................... 28

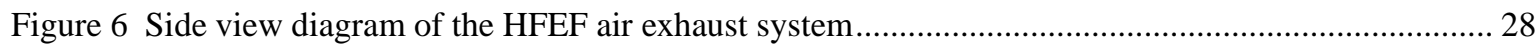

Figure 7 The ventilation and process flows meet at the bases of the HFEF stack in Room 209 .................... 29

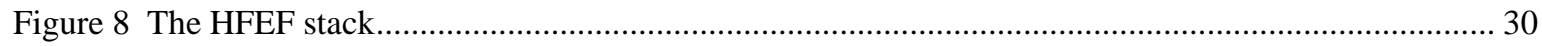

\section{Tables}

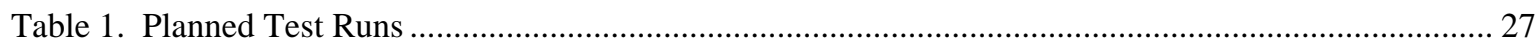

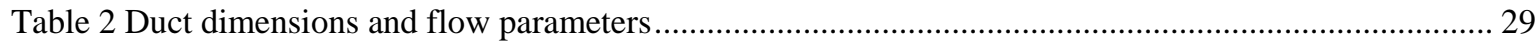

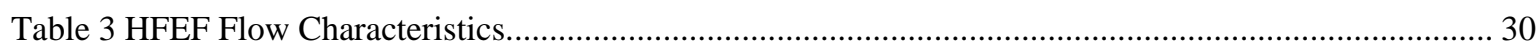

Table 4 Summary of Measurement and Test Equipment (M\&TE)................................................................ 31 


\subsection{Purpose}

The purpose of this series of tests is to document the concentration gradient and potential sampling system bias in the stack sampling probe located in the air exhaust stack of the Hot Fuel Examination Facility (HFEF). During previous testing to evaluate the HFEF exhaust stack, a significant concentration gradient was observed in the stack at a plane approximately $20 \mathrm{ft}$ from the base of the stack.

Additionally, when the tracer gas concentration was measured through the existing stack sampling system (from the sample canister connected to the sampling line; see Figure 4b), the concentration was an order of magnitude lower than expected from the measurements made in the stack. The tests conducted under this test plan will explore these issues further and document the characteristics of the tracer mixing and measurements. These data will be used to support the air emissions permit for the HFEF.

This work is performed by Pacific Northwest National Laboratory (PNNL) for Idaho National Laboratory (INL) under Memorandum Purchase Order No. 00097184 and under Contract No. DE-AC05-76RL01830 according to the statement of work SOW-8469 Revision 1 issued by INL.

The tests will be conducted by PNNL personnel at the HFEF and in observance of INL safety and radiation protection requirements. Assistance will be provided by INL staff.

Section 6 of this test plan details the quality program that is followed for this project and testing. Work will be performed to the quality requirements of American Society of Mechanical Engineers (ASME) NQA-1-2000, Quality Assurance Requirements for Nuclear Facility Applications, Part 1, Requirements for Quality Assurance Programs for Nuclear Facilities, and ASME NQA-1-2000, Part IV, Subpart 4.2, Graded Approach Application of Quality Assurance Requirements for Research and Development. These quality requirements are implemented through the Stack Monitoring Project (STMON) QA Plan (QASTMON-0001, QAP). This project is graded as technology level "Development Work" in accordance with the quality assurance (QA) program.

\subsection{Objectives}

The objective of this test plan is to describe testing that will be conducted to document the concentration gradient in the HFEF stack near the location of the stack sampling system, and to determine whether the current stack sampling system has a measurement bias that results in reported concentrations that are significantly lower than the concentrations within the stack at the sample inlet position. This determination requires a series of tests that are described below under Section 4.0, "Test Conditions."

This test plan outlines the testing that will be conducted at the HFEF. The test conditions described in this test plan are assumed to represent the normal operating condition of the air exhaust system. Consideration will be given to tests runs at alternate operating conditions as they are identified. Typically, the tests are conducted at flowrates that bracket the range of expected flowrates or fan operating conditions.

\subsection{Success Criteria}

Completion of the work described in the test plan will document the gaseous tracer concentration gradient in the stack near the sampling probe position, and determine whether there is a bias in the concentrations measured by the air sampling system. 


\subsection{Test Conditions}

A specific test procedure and test instructions will be followed to complete the tests to measure the gradient across a cross-section and to determine stack sampling system bias. The basic series of tests include the following:

- Measurement of gas tracer concentration gradient

- Measurement of sampling system bias

These tests are described in sub-sections to this section. The details concerning the constraints for conducting the basic tests, and an initial outline of the number and type of tests to be conducted on the HFEF stack are also included.

\subsection{Gas Tracer Measurements}

The approach to assessing the tracer gradient and sampling system bias is outlined below.

1. Measure the $\mathrm{SF}_{6}$ gradient

a. Inject a regulated amount of tracer at one of the points indicated by the arrows in Figure 1

b. Measure average concentration using the standard procedure described by Glissmeyer and Flaherty (2010)

i. Make measurements from the four ports on North side of stack

ii. Use five points per port so one of the points is at the same depth as the $\mathrm{E} / \mathrm{W}$ traverse. (Ports on the north are not co-planar with the port on the west, so the measurement locations will not be coincident.)

c. Measure the $\mathrm{SF}_{6}$ concentration gradient near the sampling nozzle

i. This may be done using either the 1-inch port or the 6-inch flanged pipe on the West side of the stack. The 1-inch port is less than 6 inches below the inlet of the shrouded nozzle. The flanged pipe is about even with the bottom of the shrouded nozzle (See Figure 2)

ii. Space measurement points to include the points that nearly align with the center points from the measurement grid used for the four North ports and with the inlet of the shrouded nozzle. (Preliminary sampling grid is shown in Figure 3)

2. Measure the sampling system bias

a. Measure $\mathrm{SF}_{6}$ concentration near the sampling nozzle via one of the test ports used above. (We expect that will be the 1-inch port on the West side of the stack.) The results of Step 1c will provide guidance on whether the sampling location is fixed or moving to cover a small span of points near the shrouded nozzle.

b. Simultaneously measure $\mathrm{SF}_{6}$ concentrations through the sampling system at one of the locations shown in Figure 4.

3. Repeat tests \#1 and \#2 as needed (assumed to include as many runs as can be done in two days). 

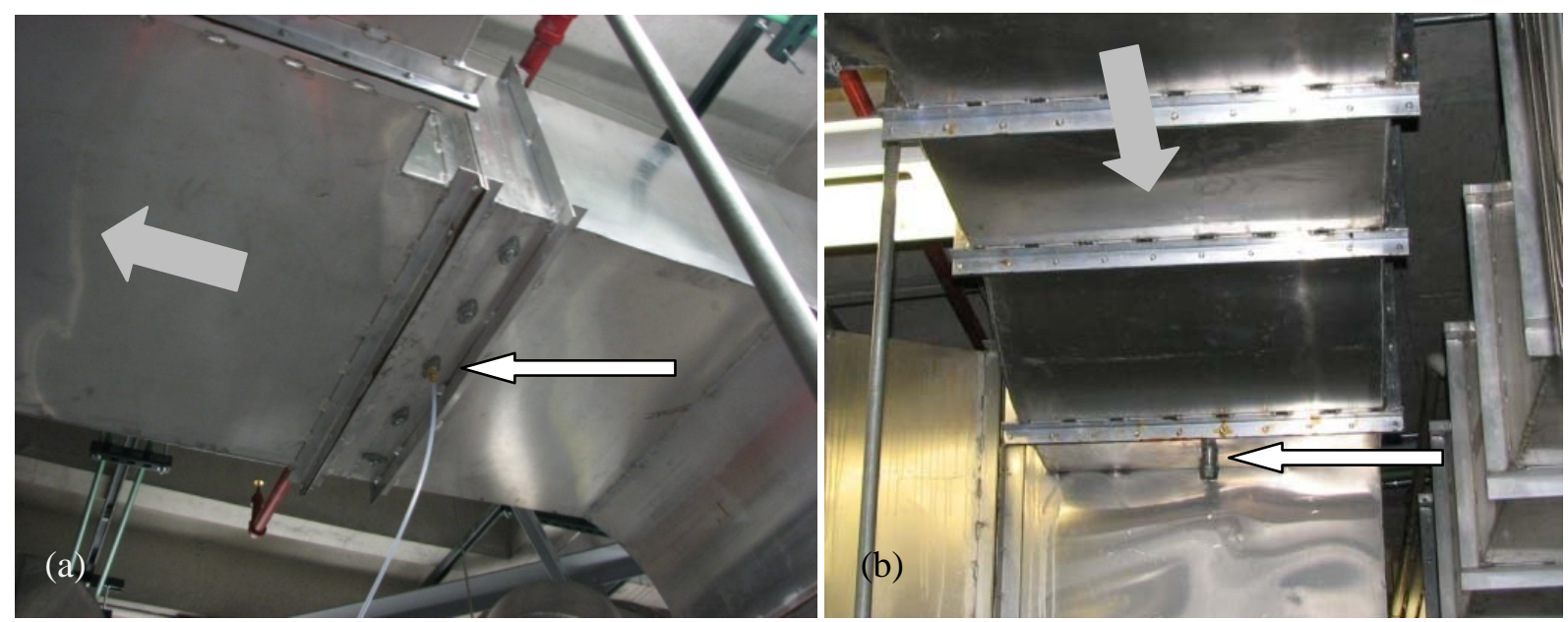

Figure 8 Tracer injection locations in the process duct in Room 209. The wide, grey arrows indicate the direction of air flow in the duct.

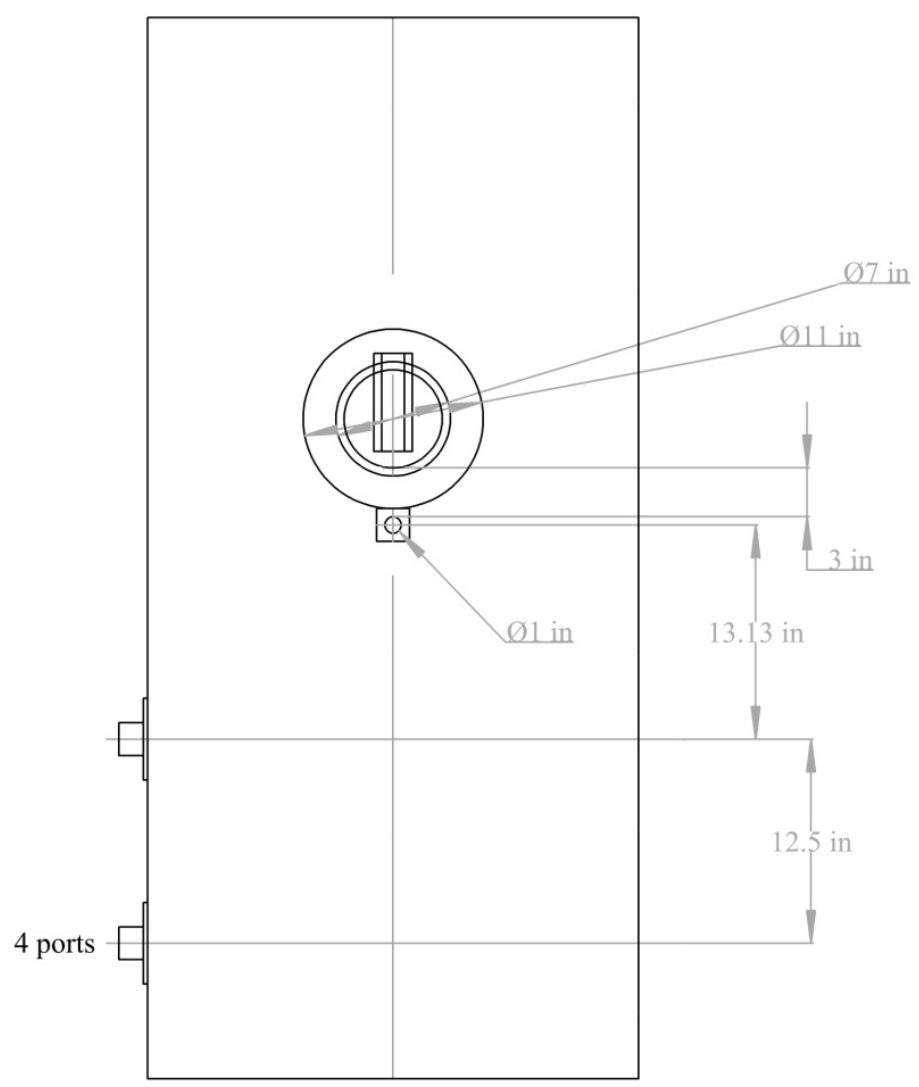

Figure 9 Two ports on the West side of the HFEF stack. 


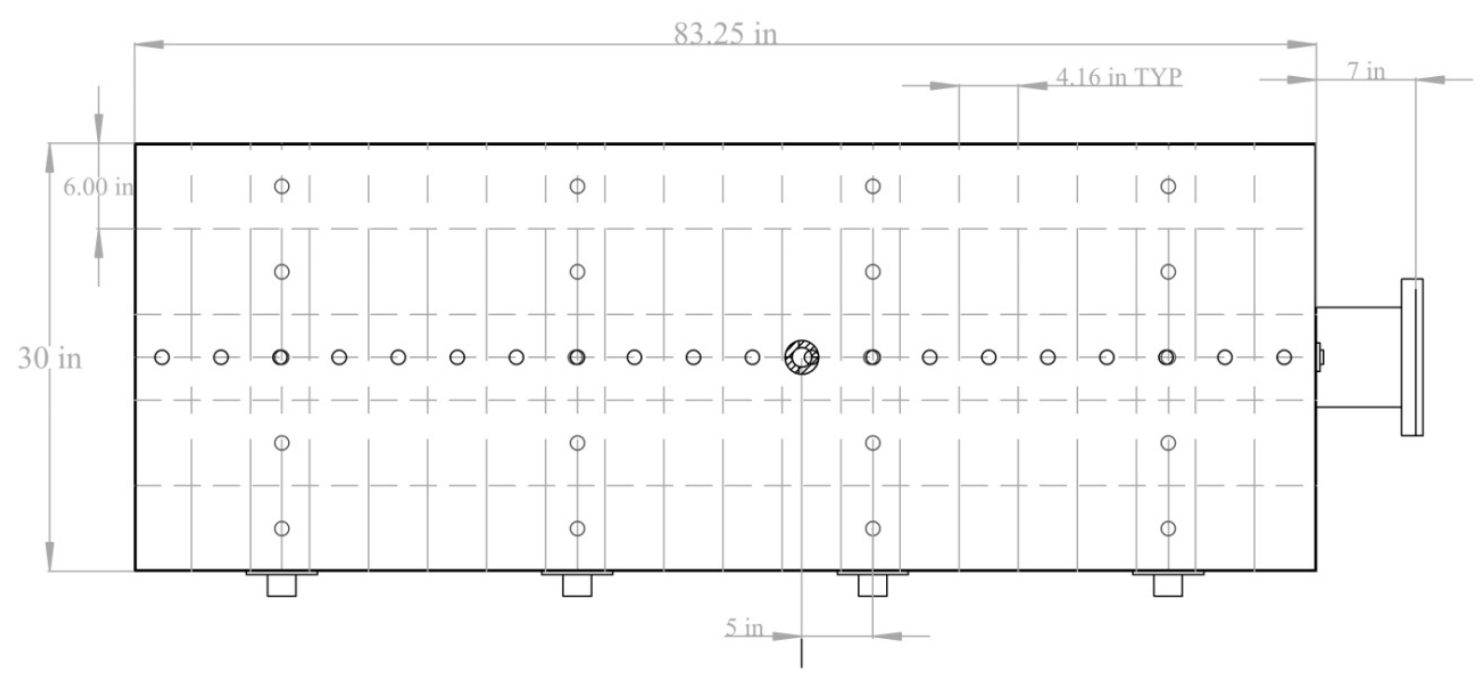

Figure 10 Preliminary sampling grid through the four ports on the North side of the HFEF stack and through the West side port.
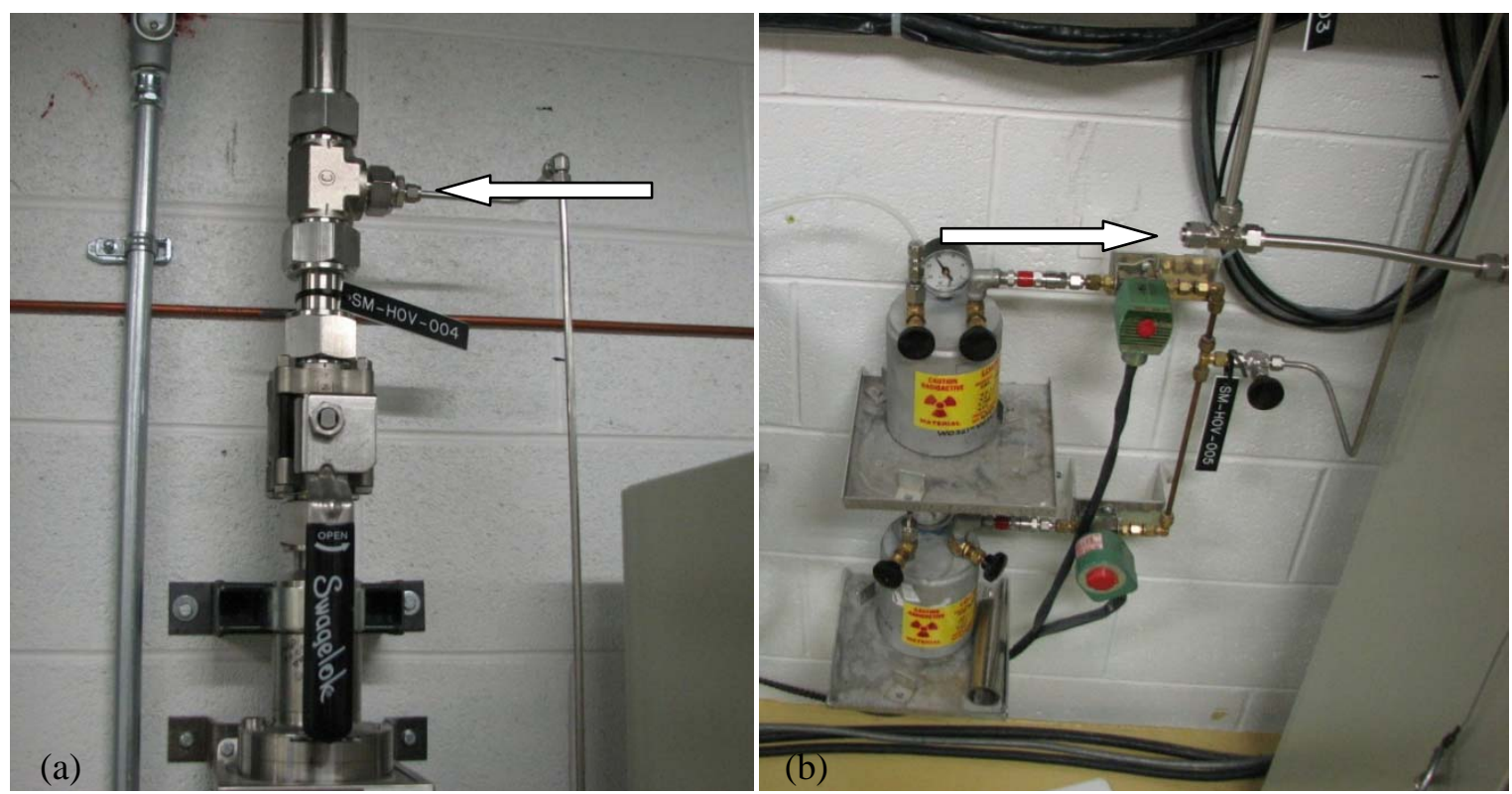

Figure 11 Sampling system tracer measurement locations in hall outside Room 209.

A uniform contaminant concentration at the sampling plane enables the extraction of a sample that represents the mean concentration of the stack effluent. Sulfur hexafluoride is used as a tracer gas injected into the air downstream of the fan. The tracer concentration is then measured at the sampling location using a photoacoustic gas analyzer. ${ }^{3}$ For the $\mathrm{SF}_{6}$ gradient measurements, the tracer concentration is measured three times at each grid point, and each measurement is recorded. The measurements at each grid point are averaged and are used to calculate the mean and standard deviation of concentration for the

\footnotetext{
${ }^{3}$ Photoacoustic Gas Monitor Model 1302, Innova AirTech Instruments A/S, Energivej 30, 2750 Ballerup, Denmark, Tel. +45 442001 01, www.innova.dk.
} 
sampling location. Previous testing indicated that there is a strong gradient across the East-West width of the stack. Therefore, the tests to measure the $\mathrm{SF}_{6}$ gradient will document the gradient that exists in the stack as a reference for the facility to use in computing the difference between the concentration measured by the stack sampling system and the stack mean concentration.

For the sampling system bias measurements, the $\mathrm{SF}_{6}$ concentration will be measured concurrently at a single point in the stack and from a single point along the sampling system line. Each measurement will be made about 10 times to establish a statistically sound mean concentration for comparison between the two locations. The sampling system bias measurements will document whether there is a difference between the concentration measured by the stack sampling system and the concentration in the stack at the sampling system probe location. The 6-inch flanged pipe may be equipped with a Plexiglas cover for visual inspection of the sampling system probe. A video camera may also be utilized to evaluate the shrouded probe condition as necessary.

The $\mathrm{SF}_{6}$ analyzer response is checked with calibration standards before conducting the test series to verify that the instrument responds adequately to changes in concentration. Typically, the tests use a single instrument, and systematic bias in the instrument response has no effect on the uniformity measurements. Under these testing conditions, if the indicated concentration is within $20 \%$ of the standard, the response is acceptable. For the sampling system bias tests, two instruments will be utilized concurrently. As a result, it will be important to also recognize any systematic instrument biases between the two instruments when reporting the differences between the two sampling locations.

PNNL procedure EMS-JAG-01, Test to Determine Uniformity of a Tracer Gas at a Sampler Probe, is used for this test. Each gradient test run will take about 90 minutes, while the bias test will take about 30 minutes. A test instruction will be issued specifically for each of these tests. Table 3 lists the planned tests to accomplish the goals of this work. Field observations may inform the execution of these tests.

Table 3. Planned Test Runs

\begin{tabular}{|c|c|c|c|}
\hline $\begin{array}{c}\text { Test } \\
\text { Prefix }\end{array}$ & Test Objective & Test Port & $\begin{array}{c}\text { Nr. Measurement } \\
\text { Points }\end{array}$ \\
\hline GT- & $\begin{array}{c}\text { Planar mean } \\
\text { concentration }\end{array}$ & 4 North Ports & 20 \\
\hline GT- & $\begin{array}{c}\text { E-W concentration } \\
\text { gradient }\end{array}$ & 1 West Port & 15 \\
\hline BT- & Sample System Bias & $\begin{array}{c}1 \text { " West Port and } \\
\text { Sample System Line } \\
\left(2^{\text {nd }} \text { Floor }\right)\end{array}$ & $\begin{array}{c}2 \\
(1 \text { in the stack, } \\
1 \text { from the line })\end{array}$ \\
\hline
\end{tabular}

\subsection{Exhaust System Geometry and Flow}

Figure 5 is a plan view diagram of the air exhaust system provided by INL. The airflow is comprised of the filtered process off-gas and the filtered ventilation off-gas. These two streams join at the bottom of the stack. Figure 6 (also provided by INL) is a diagram of the side view of the stack. 


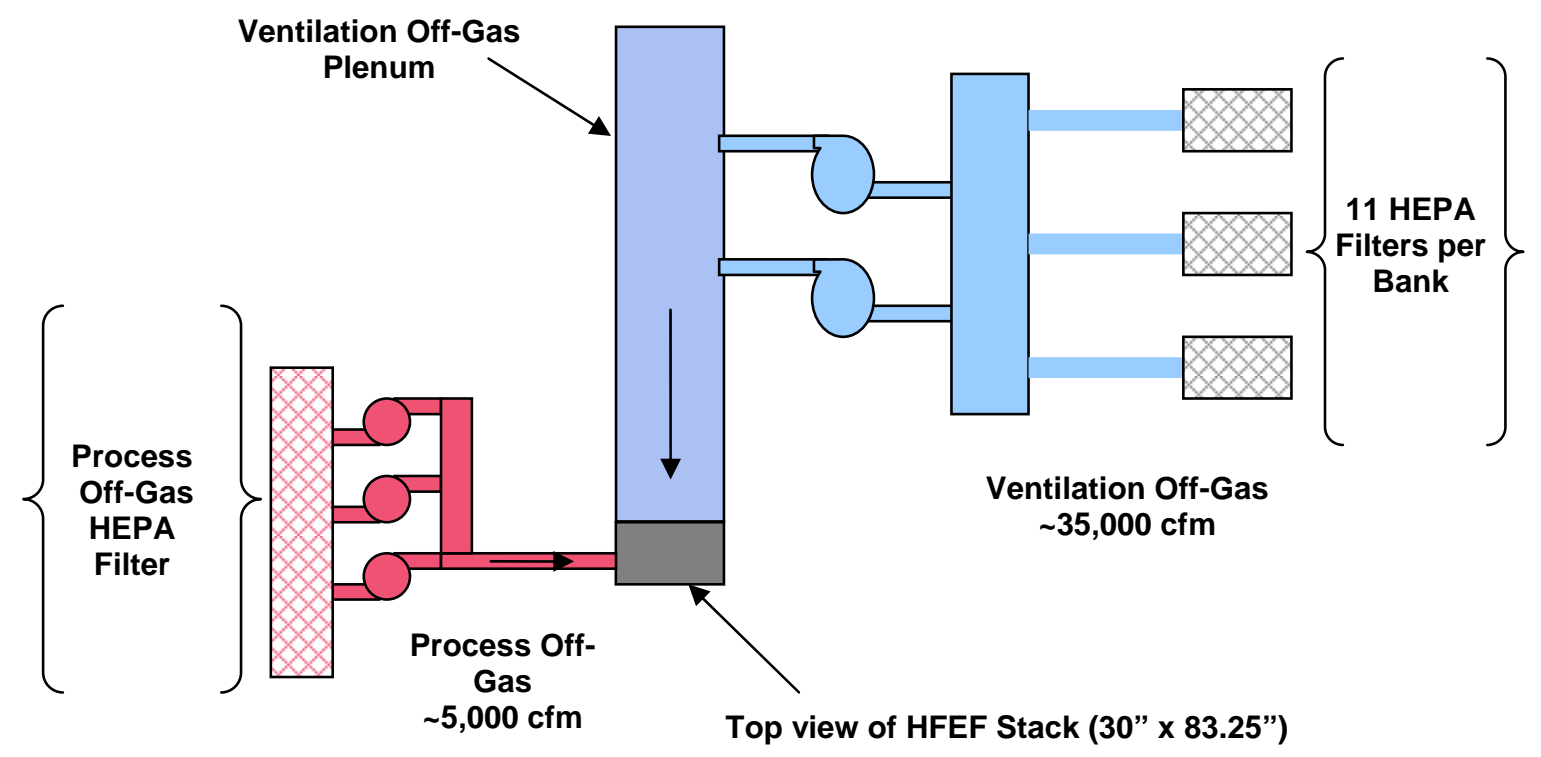

Figure 12 Plan view diagram of the HFEF air exhaust system

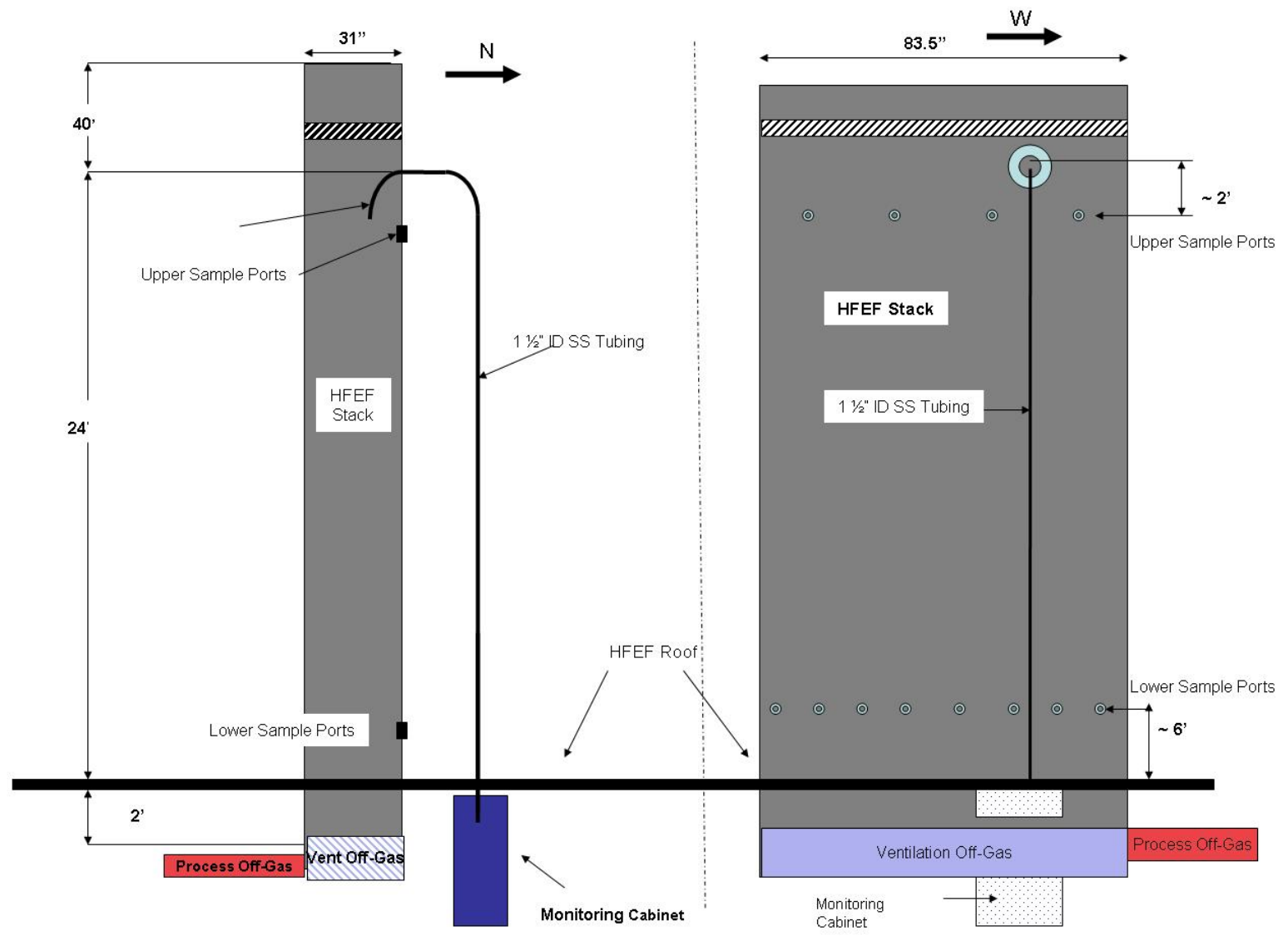

Figure 13 Side view diagram of the HFEF air exhaust system 
Table 4 lists the duct dimensions, approximate airflows and average air velocity for the building ventilation (clean) and process (potentially contaminated) streams. At the junction where the ventilation and process streams meet, the process air velocity is about $33 \%$ less than the velocity of the ventilation air. The two streams are physically separated as they turn upwards into the base of the stack, and combine as two parallel (rather than orthogonal) flows. Figure 7 shows how the ducts for the two streams meet at the base of the HFEF stack. The large difference in air velocities, in conjunction with the geometry of the flow junction, results in poor mixing of the two air streams as observed in the July stack tests (Glissmeyer and Flaherty, 2010).

Table 4 Duct dimensions and flow parameters

\begin{tabular}{|c|c|c|c|c|c|c|}
\hline Duct & $\begin{array}{c}\text { Width } \\
\text { in. }\end{array}$ & $\begin{array}{c}\text { Depth } \\
\text { in. }\end{array}$ & $\begin{array}{c}\text { Area } \\
\text { sq. in. }\end{array}$ & $\begin{array}{c}\text { Area } \\
\text { sq. ft. }\end{array}$ & $\begin{array}{c}\text { Flow } \\
\text { cfm }\end{array}$ & $\begin{array}{c}\text { Mean } \\
\text { Velocity } \\
\text { fpm }\end{array}$ \\
\hline Ventilation & 76 & 30 & 2280 & 15.83 & 35000 & 2211 \\
\hline Process & 30 & 18 & 486 & 3.38 & 5000 & 1481 \\
\hline
\end{tabular}

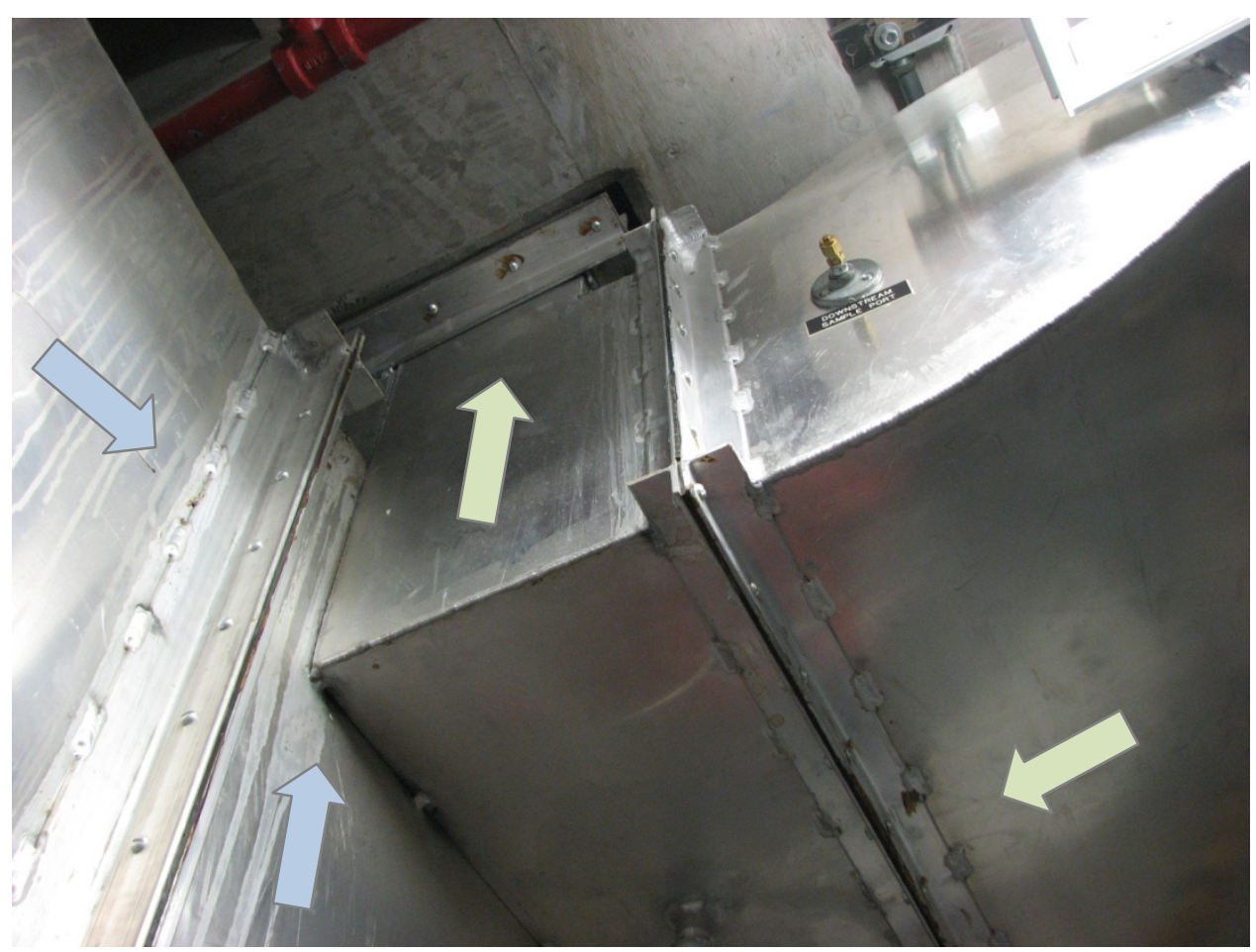

Figure 14 The ventilation and process flows meet at the bases of the HFEF stack in Room 209. The blue arrows represent the flow direction of the ventilation stream, while the green arrows represent the process stream. The process stream duct is separated from the ventilation stream by the duct wall (seen as the seam between the upward-pointing green arrow and the duct stiffener to its left).

Table 5 lists key air flow parameters for the exhaust stack. The flow conditions are typically constant, with a brief $(<5$ minute) drop in flow rate during planned monthly tests of auxiliary power. There should 
be no fan changes or maintenance during the conduct of these tests. Figure 8 shows a portion of the stack with the sampling platform (for measurements from the four North ports) as well as the two West ports.

Table 5 HFEF Flow Characteristics

\begin{tabular}{|l|c|}
\hline \multicolumn{1}{|c|}{ Characteristic } & HFEF Stack \\
\hline Stack Cross-sectional Length $\mathrm{x}$ Width & $30 \mathrm{x} \mathrm{83.25} \mathrm{in}$ \\
\hline Effective Diameter 2(L*W)/(L+W) & $3.78 \mathrm{ft}$ \\
\hline Reynolds Number & $>1.0 \mathrm{E}+6$ \\
\hline Shrouded Probe distance to nearest upstream disturbance & 6.9 duct dia. \\
\hline Shrouded Probe distance to nearest downstream disturbance & 10.6 duct dia. \\
\hline
\end{tabular}

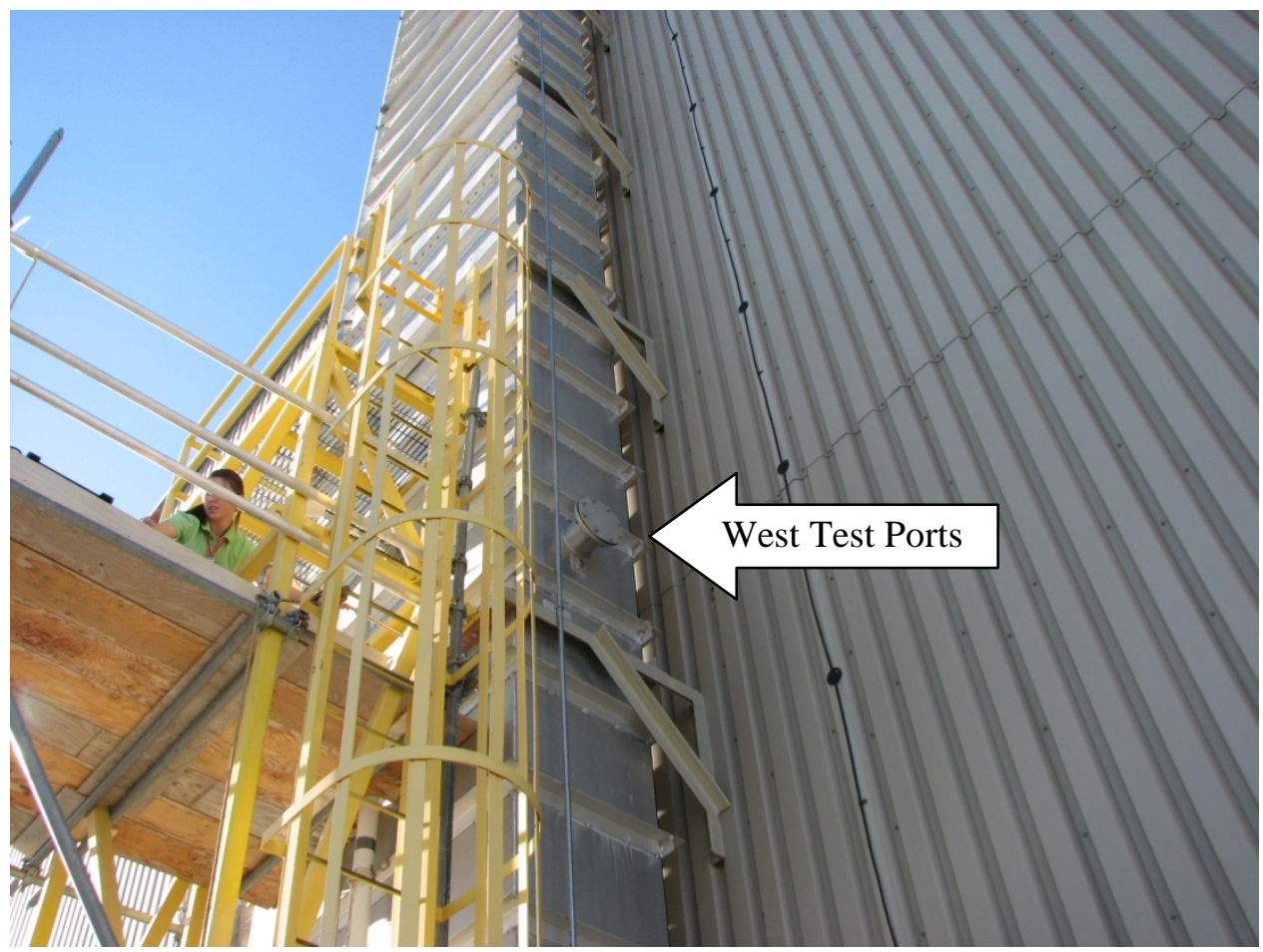

Figure 15 The HFEF stack

\subsection{Measuring and Testing Equipment}

The equipment needed to perform the testing is listed in Table 6. 
Table 6 Summary of Measurement and Test Equipment (M\&TE)

\begin{tabular}{|c|c|c|c|}
\hline M\&TE & Application & Range & Tolerance \\
\hline $\begin{array}{c}\text { Electronic air velocity } \\
\text { meter and thermometer }\end{array}$ & Single point measurement & $0-8000 \mathrm{ft} / \mathrm{min}$ & $\begin{array}{c}\text { Greater of } \pm 3 \% \text { of } \\
\text { reading or } 3 \mathrm{ft} / \mathrm{min}\end{array}$ \\
\cline { 3 - 4 } & & $32-140^{\circ} \mathrm{F}$ & $\pm 2^{\circ} \mathrm{F}$ \\
\hline $\mathrm{SF}_{6}$ Tracer gas analyzer & Gas tracer uniformity & See below & See below \\
\hline $\mathrm{SF}_{6}$ calibration standards & Gas tracer uniformity & $0.1 \mathrm{ppm}$ & $\pm 20 \%$ \\
\cline { 3 - 4 } & & $5 \mathrm{ppm}$ & $\pm 10 \%$ \\
\hline $\begin{array}{c}\text { Tape measure, caliper } \\
\text { and ruler }\end{array}$ & $\begin{array}{c}\text { Stack dimensions, tracer } \\
\text { injection position }\end{array}$ & N.A. & $\pm 0.125 \mathrm{in}$. \\
\hline $\begin{array}{c}\text { Portable weather station } \\
\text { Environmental conditions } \\
\text { (barometric pressure, }\end{array}$ & $\begin{array}{c}23.45-31.01 \mathrm{in} \mathrm{Hg} \\
800-1050 \mathrm{mbar}\end{array}$ & $\pm 0.1477 \mathrm{in} . \mathrm{Hg}$ \\
\cline { 2 - 4 } & $\begin{array}{c}0-55^{\circ} \mathrm{C} \\
\text { temperature and humidity) }\end{array}$ & $\pm 1.8^{\circ} \mathrm{F} / \pm 1^{\circ} \mathrm{C}$ \\
\hline
\end{tabular}

\subsection{Data Records and Reporting}

The data from each test run will be recorded in a data sheet. The data reduction will be performed by PNNL using Microsoft Excel with a worksheet for each data sheet. The data transfers into the worksheet will be independently verified. The worksheet will be independently verified to ensure that it correctly performs its calculations in accordance with the QA procedures described in Section 6. Each completed and quality-assured worksheet will be included in the final letter report and data package. The handrecorded work sheets become part of the Test Instruction record.

Equipment operational data may be collected electronically or by hand to monitor or evaluate the test equipment. These operational data are not quality-affecting data and may not be included in the data package. A letter report and data package will be prepared and provided at the conclusion of the current project.

\subsection{Application of Quality Assurance Requirements}

The Pacific Northwest National Laboratory QA program is based upon the requirements as defined in the U.S. Department of Energy (DOE) Order 414.1C, Quality Assurance and 10 CFR 830, Energy/Nuclear Safety Management, and Subpart A-Quality Assurance Requirements (a.k.a., the Quality Rule). PNNL has chosen to implement the following consensus standards in a graded approach:

- ASME NQA-1-2000, Quality Assurance Requirements for Nuclear Facility Applications, Part 1, Requirements for Quality Assurance Programs for Nuclear Facilities.

- $\quad$ ASME NQA-1-2000, Part II, Subpart 2.7, Quality Assurance Requirements for Computer Software for Nuclear Facility Applications.

- ASME NQA-1-2000, Part IV, Subpart 4.2, Graded Approach Application of Quality Assurance Requirements for Research and Development.

The QA plan for the STMON implements the requirements of ASME NQA-1-2000, Part 1:

"Requirements for Quality Assurance Programs for Nuclear Facilities," which is presented in two parts. 
Part 1 of the QA manual describes the graded approach developed by applying NQA-1-2000, Subpart 4.2, "Guidance on Graded Application of Quality Assurance (QA) for Nuclear-Related Research and Development" to the requirements based on the type of work scope. Part 2 of the QA manual lists all of the NQA-1-2000 requirements that the project is implementing for the different technology levels of research and development (R\&D) work. Requirements are clearly listed for the technology level they apply to.

This project recognizes that QA applies in varying degrees to a broad spectrum of R\&D in the technology life cycle. For this project, the requirements associated with development work apply as the data will be used for applying air discharge permits:

- DEVELOPMENTAL WORK: Development work consists of research tasks moving toward technology commercialization. These tasks still require a degree of flexibility, and there is still a degree of uncertainty that exists in many cases. The role of quality on development work is to make sure that adequate controls to support movement into commercialization exist.

Records can be stored as hardcopy records in a 1-hour fire-rated container. A copy of the hardcopy record can be stored in two separate locations (dual storage) or as a scanned electronic copy in the PNNL electronic records management system (Training Requirements and Information Management SystemTRIM) (the original can be destroyed after the electronic copy has been verified). Electronic files of testing data will be retained until report publication. At that time, data files can be requested by the client before they are removed from storage.

\subsection{Conduct of Experimental and Analytical Work}

Experiments that are not method-specific are performed in accordance with QA-STMON-1103 "Scientific Investigations—Development Work" and QA-STMON-1201 "Calibration and Control of M\&TE.” Properly calibrated measuring and test equipment is used to acquire sufficient data to produce quality results. Testing will be performed to the requirements of ANSI/HPS N13.1-1999, Sampling and Monitoring Releases of Airborne Radioactive Substances from the Stack and Ducts of Nuclear Facilities.

\subsection{Internal Data Verification and Validation}

The Stack Monitoring Project addresses internal verification and validation activities by conducting an independent technical review of the final data report in accordance with the project's procedure QASTMON-1702, "Data Entry and Data Review." This review verifies that the reported results are traceable, that inferences and conclusions are soundly based, and the reported work satisfies the Test Plan objectives. This review procedure is part of the STMON Quality Assurance Manual.

\subsection{Deviation from Statement of Work}

There are no current deviations from the Statement of Work.

\subsection{References}

1. 40 CFR 60, Appendix A, Method 1, Section 2.4, "Sample and Velocity Traverses for Stationary Sources.” 
2. ANSI/HPS N13.1-1999, Sampling and Monitoring Releases of Airborne Radioactive Substances from the Stack and Ducts of Nuclear Facilities. Health Physics Society, McLean, VA 22101.

3. Glissmeyer, J.A., 2009. EMS-JAG-01, Test to Determine Uniformity of a Tracer Gas at a Sampler Probe.

4. Glissmeyer, J.A., and J.E. Flaherty, 2010. Assessment of the Idaho National Laboratory Hot Fuel Examination Facility Stack Monitoring Site for Compliance with ANSI/HPS N13.1 1999.

PNNL-19659, RPT-STMON-007, Pacific Northwest National Laboratory, Richland, WA 99352.

5. Idaho National Laboratory. 2011. Statement of Work: Tracer Gradient and Sampling System Bias of the HFEF Stack Air Monitoring System. Pacific Northwest National Laboratory. SOW 8469, Rev 1. 



\section{APPENDIX 2: Data Sheets}





\section{TRACER GAS GRADIENT DATA FORM}

\begin{tabular}{|c|c|c|c|c|}
\hline \multicolumn{2}{|c|}{ Site INL HFEF } & \multicolumn{3}{|c|}{ Run No. GT-1 } \\
\hline Date & $4 / 12 / 2011$ & Start/End Time & $1615 / 1750$ & \\
\hline Testers & JAG, JEF & Fan Configuration & Both Fans & \\
\hline Duct Width & 83.175 in. & Stack Temp & 78 & $\operatorname{deg} F$ \\
\hline Duct Depth & 30.2 in. & Injection Point & Pipe Nipple & \\
\hline Stack X-Area & $17.4 \mathrm{ft} 2$ & Measurement Loc. & North Ports & \\
\hline
\end{tabular}

\begin{tabular}{|c|c|c|c|c|c|c|}
\hline & & |rial----> & 1 & 2 & 3 & Mean \\
\hline Port & Point & Depth, in. & \multicolumn{4}{|c|}{ ppm SF6 } \\
\hline 1 & 1 & 3.02 & 6.57 & 6.68 & 6.37 & 6.54 \\
\hline 1 & 2 & 9.06 & 4.77 & 4.62 & 4.78 & 4.72 \\
\hline 1 & 3 & 15.09 & 3.05 & 3.11 & 3.40 & 3.19 \\
\hline 1 & 4 & 21.13 & 1.74 & 2.28 & 2.55 & 2.19 \\
\hline 1 & 5 & 27.17 & 1.10 & 1.44 & 1.33 & 1.29 \\
\hline 2 & 1 & 3.02 & 2.00 & 2.10 & 2.16 & 2.09 \\
\hline 2 & 2 & 9.06 & 2.64 & 2.76 & 2.82 & 2.74 \\
\hline 2 & 3 & 15.09 & 2.26 & 2.65 & 2.37 & 2.43 \\
\hline 2 & 4 & 21.13 & 2.01 & 2.20 & 1.86 & 2.02 \\
\hline 2 & 5 & 27.17 & 1.44 & 1.59 & 1.76 & 1.60 \\
\hline 3 & 1 & 3.02 & 0.287 & 0.169 & 0.211 & 0.222 \\
\hline 3 & 2 & 9.06 & 0.352 & 0.175 & 0.183 & 0.237 \\
\hline 3 & 3 & 15.09 & 0.184 & 0.181 & 0.166 & 0.177 \\
\hline 3 & 4 & 21.13 & 0.129 & 0.132 & 0.217 & 0.159 \\
\hline 3 & 5 & 27.17 & 0.151 & 0.135 & 0.109 & 0.132 \\
\hline 4 & 1 & 3.02 & 0.0181 & 0.0311 & 0.0287 & 0.026 \\
\hline 4 & 2 & 9.06 & 0.0394 & 0.0246 & 0.0316 & 0.032 \\
\hline 4 & 3 & 15.09 & 0.0277 & 0.0451 & 0.0164 & 0.030 \\
\hline 4 & 4 & 21.13 & 0.0356 & 0.0324 & 0.0325 & 0.034 \\
\hline 4 & 5 & 27.17 & 0.0415 & 0.0316 & 0.0254 & 0.033 \\
\hline & $\overline{\text { erages }}$ & & 1.442 & 1.519 & 1.521 & 1.494 \\
\hline
\end{tabular}

Stack Flow (Control Rm) Stack Flow (KURZ) Tracer tank pressure Injection flowmeter Stack Temp

Center Pt. air vel. Sampling flowmeter Ambient pressure Ambient humidity Ambient Temp B\&K vapor correction Back-Gd gas

No. Bk-Gd samples

\begin{tabular}{|c|c|c|}
\hline Start & Finish & \\
\hline $63 \%$ & $63 \%$ & $\%$ of 51,900 \\
\hline 32,406 & 32,426 & $\mathrm{cfm}$ \\
\hline 250 & 300 & psig \\
\hline 3.75 & 3.75 & Ipm as $\mathrm{CO} 2$ \\
\hline 78 & 78 & ${ }^{\circ} \mathrm{F}$ \\
\hline 1400 & 1470.0 & fpm \\
\hline 10 & 10 & Ipm \\
\hline 834.00 & 834.00 & mbar \\
\hline 32 & 32 & $\mathrm{RH}$ \\
\hline 51 & 53 & ${ }^{\circ} \mathrm{F}$ \\
\hline $\mathrm{Y}$ & $\mathrm{Y}$ & $\mathrm{Y} / \mathrm{N}$ \\
\hline $26,2,22,17$ & $40,61,59,21$ & ppb \\
\hline 4 & 4 & r \\
\hline
\end{tabular}

Notes: $\quad 32,300-32,600 \mathrm{cfm}$ on CMS2000/KURZ.

Can't reach point 5 due to cross-beam 32,406 on CMS2000/KURZ during Port 2 measurements at 16:57. 32,426 on CMS2000/KURZ at the end of the test.

Background measurements at Port 1, Point 1.

Stack air velocity \& temperature at Port 2 near center. Avg 5 readings.

Hi-Q \#1 pump.

\begin{tabular}{|c|c|c|c|c|}
\hline Mean & $\frac{\mathrm{ppm}}{1.49}$ & $\begin{array}{l}\text { Deviation } \\
\text { from mean }\end{array}$ & \multirow{3}{*}{$\begin{array}{l}\text { Std. Dev. } \\
\text { cov as \% }\end{array}$} & \multirow[b]{2}{*}{1.80} \\
\hline Min Point & 0.03 & $-98.3 \%$ & & \\
\hline Max Point & 6.54 & $337.7 \%$ & & 120.5 \\
\hline \multicolumn{3}{|l|}{ Instruments Used: } & \multicolumn{2}{|c|}{ Cal Due / Check } \\
\hline \multicolumn{3}{|c|}{ B\&K 1302 Gas Analyzer SN 1804888} & \multicolumn{2}{|c|}{$4 / 12 / 2011$} \\
\hline \multicolumn{3}{|c|}{ TSI VelociCalc SN 209060} & \multicolumn{2}{|r|}{$6 / 25 / 2011$} \\
\hline \multicolumn{3}{|c|}{ Omega FMA-2606A flowmeter SN 27708} & \multicolumn{2}{|r|}{ N/A } \\
\hline \multicolumn{3}{|c|}{ Fisher Weather Station SN 61876141} & \multicolumn{2}{|r|}{$5 / 17 / 2011$} \\
\hline
\end{tabular}

\begin{tabular}{|llc|lcc|}
\hline $\begin{array}{l}\text { Entries made by: } \\
\text { Signature/date }\end{array}$ & $\begin{array}{l}\text { Julia Flaherty } \\
\text { On File with Original }\end{array}$ & $4 / 12 / 2011$ & Technical Data Review performed by: & Carmina Arimescu \\
Signature/date & Via Email & $5 / 9 / 2011$ \\
& & & & \\
\end{tabular}




\section{TRACER GAS GRADIENT DATA FORM}

$\begin{aligned} \text { Site } & \text { INL HFEF } \\ \text { Date } & \frac{4 / 13 / 2011}{\text { Testers }} \\ \text { JAG, JEF } & \frac{83.175}{\text { in. }} \\ \text { Duct Width } & \frac{30.2}{\mathrm{in} .} \\ \text { Duct Depth } & 17.4 \mathrm{ft} 2\end{aligned}$

Run No. GT-2

Start/End Time 10:00/11:31

Fan Configuration Both Fans

Stack Temp $77.5 \quad \operatorname{deg} F$

Injection Point Pipe Nipple

Measurement Loc. West Port

\begin{tabular}{|c|c|c|c|c|c|c|}
\hline & & Trial----> & 1 & 2 & 3 & Mean \\
\hline Port & Point & Depth, in. & \multicolumn{4}{|c|}{ ppm SF6 } \\
\hline W & 1 & 2.08 & 0.659 & 0.564 & 0.841 & 0.69 \\
\hline W & 2 & 6.24 & 0.916 & 0.890 & 0.994 & 0.93 \\
\hline W & 3 & 10.40 & 1.09 & 0.928 & 1.31 & 1.11 \\
\hline $\mathrm{W}$ & 4 & 14.56 & 1.28 & 1.40 & 1.51 & 1.40 \\
\hline W & 5 & 18.71 & 1.48 & 1.48 & 1.56 & 1.51 \\
\hline W & 6 & 22.87 & 1.32 & 1.54 & 1.55 & 1.47 \\
\hline W & 7 & 27.03 & 1.23 & 1.26 & 1.37 & 1.29 \\
\hline W & 8 & 31.19 & 1.04 & 0.956 & 1.12 & 1.04 \\
\hline $\mathrm{W}$ & 9 & 35.35 & 0.604 & 0.592 & 0.815 & 0.67 \\
\hline W & 10 & 39.51 & 0.480 & 0.491 & 0.558 & 0.51 \\
\hline W & 11 & 43.67 & 0.309 & 0.293 & 0.375 & 0.326 \\
\hline W & 12 & 47.83 & 0.230 & 0.196 & 0.151 & 0.192 \\
\hline W & 13 & 51.98 & 0.0941 & 0.166 & 0.102 & 0.121 \\
\hline $\mathrm{W}$ & 14 & 56.14 & 0.0831 & 0.0832 & 0.0699 & 0.079 \\
\hline W & 15 & 60.30 & 0.0336 & 0.0457 & 0.0581 & 0.046 \\
\hline W & 16 & 64.46 & 0.0289 & 0.0208 & 0.0339 & 0.028 \\
\hline W & 17 & 68.62 & 0.0218 & 0.0372 & 0.0270 & 0.029 \\
\hline W & 18 & 72.78 & 0.0348 & 0.0777 & 0.0375 & 0.050 \\
\hline $\mathrm{W}$ & 19 & 76.94 & 0.0233 & 0.0439 & 0.0293 & 0.032 \\
\hline W & 20 & 81.10 & 0.0315 & 0.0352 & 0.0428 & 0.037 \\
\hline & rages & & 0.549 & 0.555 & 0.628 & 0.577 \\
\hline
\end{tabular}

Stack Flow (Control Rm)

Stack Flow (KURZ)

Tracer tank pressure

Injection flowmeter

Stack Temp

Center Pt. air vel.

Sampling flowmeter

Ambient pressure

Ambient humidity

Ambient Temp

$B \& K$ vapor correction

Back-Gd gas

No. Bk-Gd samples

\begin{tabular}{|c|c|c|}
\hline Start & Finish & \\
\hline N/A & N/A & $\%$ of 51,900 \\
\hline 32,370 & 32,209 & $\mathrm{cfm}$ \\
\hline 250 & 300 & psig \\
\hline 3.75 & 3.75 & Ipm as $\mathrm{CO} 2$ \\
\hline 77 & 78 & ${ }^{\circ} \mathrm{F}$ \\
\hline 1440 & 1490.0 & fpm \\
\hline 10 & 10 & Ipm as $\mathrm{CO} 2$ \\
\hline 832.00 & 831.00 & mbar \\
\hline 51 & 38 & $\mathrm{RH}$ \\
\hline 44 & 53 & ${ }^{\circ} \mathrm{F}$ \\
\hline $\mathrm{Y}$ & $Y$ & Y/N \\
\hline $41,27,22,48$ & $21,43,29,38$ & $\mathrm{ppb}$ \\
\hline 4 & 4 & $\mathrm{n}$ \\
\hline
\end{tabular}

Notes: Hi-Q \#1 Pump

-11" between Port 1 centerline and West edge of stack.

So, West Port, Point 3 should match North Port 1, Point 3.

Shrouded probe expected to be near Point 8 on this grid:

actual location is near Point 11.

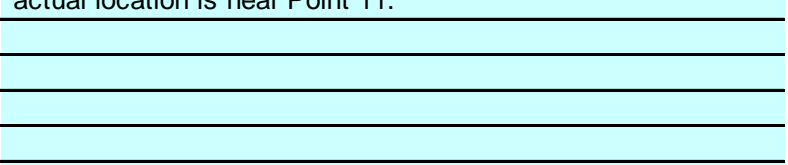

\begin{tabular}{|lrr|ll|}
\hline & ppm & Deviation & & \\
Mean & 0.58 & from mean & & \\
Min Point & 0.03 & $-95.2 \%$ & Std. Dev. & 0.56 \\
\cline { 2 - 4 } Max Point & 1.51 & $160.9 \%$ & COV as \% & 96.6 \\
\hline
\end{tabular}

Instruments Used:

Cal Due / Check

B\&K 1302 Gas Analyzer SN 1804888

$4 / 12 / 2011$

TSI VelociCalc SN $209060 \quad 6 / 25 / 2011$

Omega FMA-2606A flowmeter SN $27708 \quad$ N/A

Fisher Weather Station SN $61876141 \quad 5 / 17 / 2011$

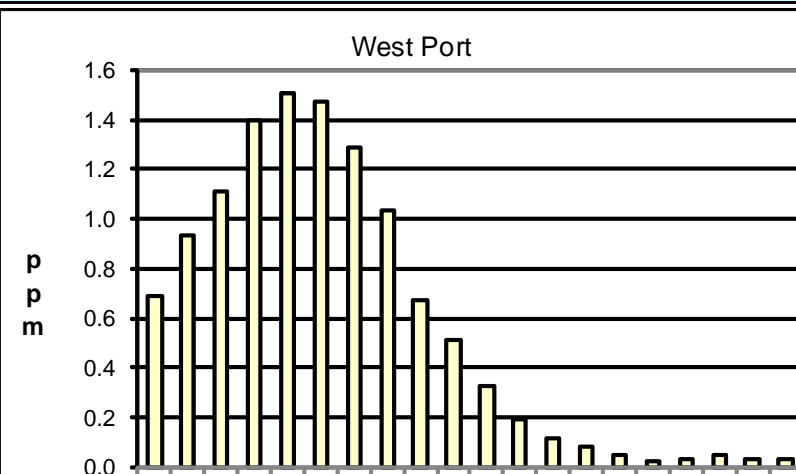

$1 \quad 2 \quad 3 \quad 4 \quad 5 \quad 6 \quad 7 \quad 8 \quad 91011121314151617181920$ Points

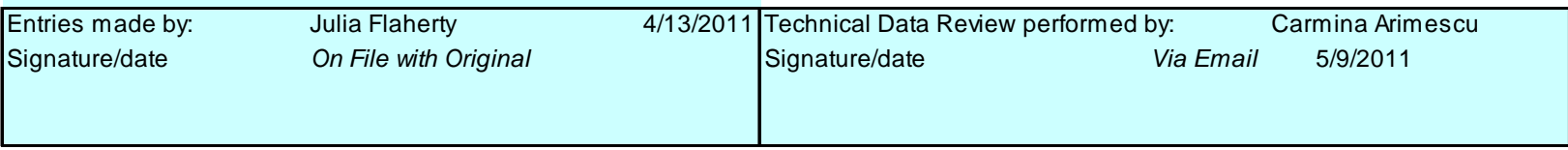




\section{TRACER GAS GRADIENT DATA FORM}

$\begin{aligned} \text { Site } & \text { INL HFFF } \\ \text { Date } & \frac{4 / 14 / 2011}{} \\ \text { Testers } & \text { JEF } \\ \text { Duct Width } & 83.175 \mathrm{in.} \\ \text { Duct Depth } & 30.2 \mathrm{in.} \\ \text { Stack X-Area } & 17.4 \mathrm{ft} 2\end{aligned}$

Run No. GT-3N

Start/End Time 15:00 / 16:35

Fan Configuration Both Fans

Stack Temp $78 \quad \operatorname{deg} F$

Injection Point Pipe Nipple

Measurement Loc. North Ports

\begin{tabular}{|c|c|c|c|c|c|c|}
\hline & & Trial----> & 1 & 2 & 3 & Mean \\
\hline Port & Point & Depth, in. & \multicolumn{4}{|c|}{ ppm SF6 } \\
\hline 1 & 1 & 3.02 & 7.22 & 5.60 & 5.81 & 6.21 \\
\hline 1 & 2 & 9.06 & 6.86 & 6.31 & 6.48 & 6.55 \\
\hline 1 & 3 & 15.09 & 5.68 & 5.52 & 4.44 & 5.21 \\
\hline 1 & 4 & 21.13 & 3.85 & 4.25 & 3.30 & 3.80 \\
\hline 1 & 5 & 27.17 & 2.22 & 3.25 & 2.34 & 2.60 \\
\hline 2 & 1 & 3.02 & 3.59 & 2.73 & 2.48 & 2.93 \\
\hline 2 & 2 & 9.06 & 2.61 & 3.14 & 2.84 & 2.86 \\
\hline 2 & 3 & 15.09 & 2.45 & 3.17 & 2.48 & 2.70 \\
\hline 2 & 4 & 21.13 & 2.32 & 2.65 & 2.38 & 2.45 \\
\hline 2 & 5 & 27.17 & 2.00 & 2.07 & 2.07 & 2.05 \\
\hline 3 & 1 & 3.02 & 0.108 & 0.223 & 0.169 & 0.167 \\
\hline 3 & 2 & 9.06 & 0.204 & 0.249 & 0.150 & 0.201 \\
\hline 3 & 3 & 15.09 & 0.230 & 0.264 & 0.198 & 0.231 \\
\hline 3 & 4 & 21.13 & 0.203 & 0.270 & 0.212 & 0.228 \\
\hline 3 & 5 & 27.17 & 0.185 & 0.228 & 0.200 & 0.204 \\
\hline 4 & 1 & 3.02 & 0.0612 & 0.0672 & 0.0829 & 0.070 \\
\hline 4 & 2 & 9.06 & 0.0547 & 0.0700 & 0.0661 & 0.064 \\
\hline 4 & 3 & 15.09 & 0.0465 & 0.0635 & 0.0686 & 0.060 \\
\hline 4 & 4 & 21.13 & 0.0539 & 0.0688 & 0.0598 & 0.061 \\
\hline 4 & 5 & 27.17 & 0.0640 & 0.0731 & - & 0.069 \\
\hline & rages. & & 2.001 & 2.013 & 1.886 & 1.936 \\
\hline
\end{tabular}

Stack Flow (Control Rm)

Stack Flow (KURZ)

Tracer tank pressure

Injection flowmeter

Stack Temp

Center Pt. air vel.

Sampling flowmeter

Ambient pressure

Ambient humidity

Ambient Temp

B\&K vapor correction

Back-Gd gas

No. Bk-Gd samples

\begin{tabular}{|c|c|c|}
\hline Start & Finish & \\
\hline N/A & $N / A$ & $\%$ of 51,900 \\
\hline -32000 & 32281 & $\mathrm{cfm}$ \\
\hline 300 & 300 & psig \\
\hline 3.75 & 3.75 & Ipm as $\mathrm{CO} 2$ \\
\hline 78 & 77 & ${ }^{\circ} \mathrm{F}$ \\
\hline 1640 & 1490 & fpm \\
\hline 10 & 10 & Ipm \\
\hline 837 & 838 & mbar \\
\hline 30 & 29 & $\mathrm{RH}$ \\
\hline 47 & 45 & ${ }^{\circ} \mathrm{F}$ \\
\hline $\mathrm{Y}$ & Y & $\mathrm{Y} / \mathrm{N}$ \\
\hline $15,39,13,20$ & $37,27,30,37$ & ppb \\
\hline 4 & & $n$ \\
\hline
\end{tabular}

\begin{tabular}{|c|c|c|c|c|}
\hline Mean & $\frac{\mathrm{ppm}}{1.94}$ & $\begin{array}{l}\text { Deviation } \\
\text { from mean }\end{array}$ & \multirow{3}{*}{$\begin{array}{l}\text { Std. Dev. } \\
\text { COV as \% }\end{array}$} & \multirow[b]{2}{*}{2.17} \\
\hline Min Point & 0.06 & $-96.9 \%$ & & \\
\hline Max Point & 6.55 & $238.3 \%$ & & 112.0 \\
\hline \multicolumn{3}{|l|}{ Instruments Used: } & \multicolumn{2}{|c|}{ Cal Due / Check } \\
\hline \multicolumn{3}{|c|}{ B\&K 1302 Gas Analyzer SN 1804888} & \multicolumn{2}{|c|}{$4 / 12 / 2011$} \\
\hline \multicolumn{3}{|c|}{ TSI VelociCalc SN 209060} & \multicolumn{2}{|r|}{$6 / 25 / 2011$} \\
\hline \multicolumn{3}{|c|}{ Omega FMA-2606A flowmeter SN 27708} & \multicolumn{2}{|r|}{ N/A } \\
\hline \multicolumn{3}{|c|}{ Fisher Weather Station SN 61876141} & \multicolumn{2}{|r|}{$5 / 17 / 2011$} \\
\hline
\end{tabular}

Notes: $\quad \mathrm{Hi}-\mathrm{Q} \# 2$

Measurements made concurently with a probe under the shrouded probe and at the north ports. At start of test, Port 2, Point 3 was 3.11 vs $3.37 \mathrm{ppm}$ at shroud.
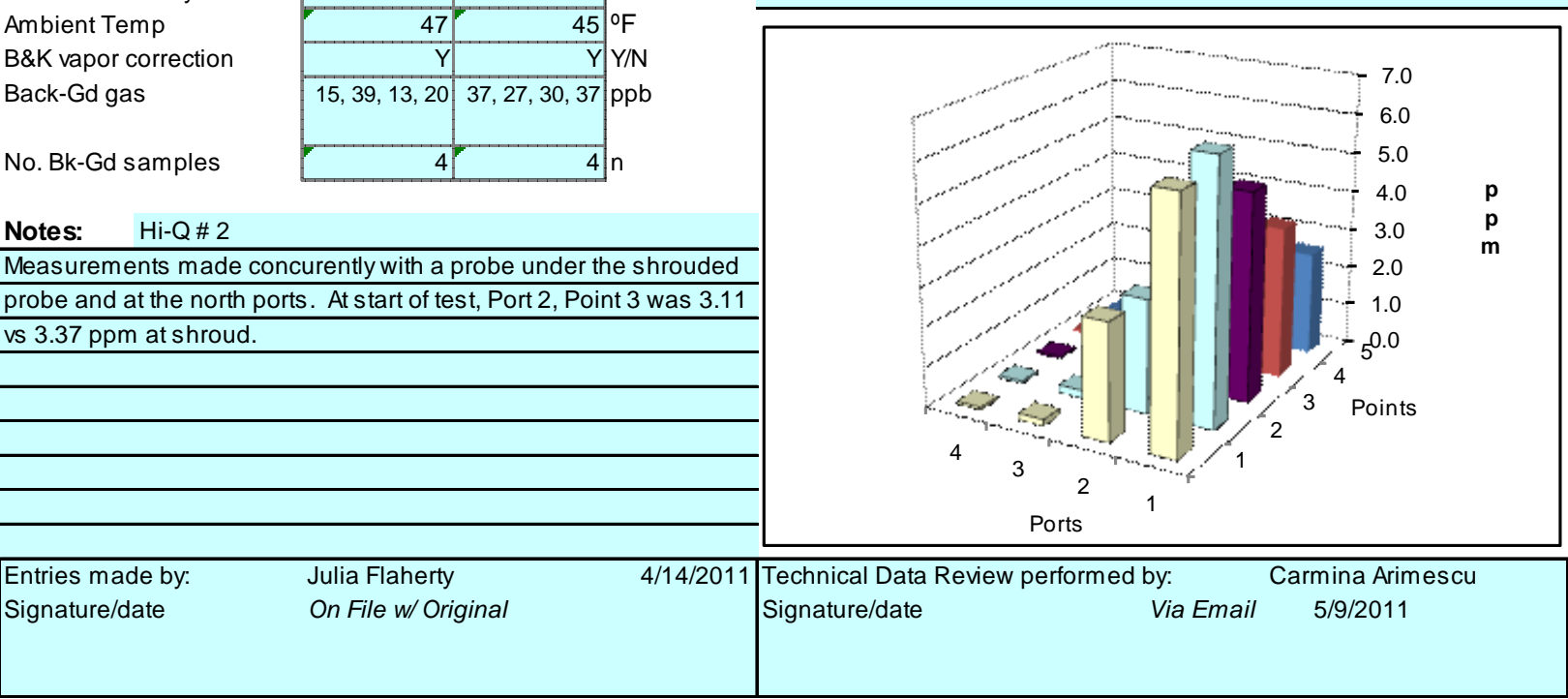


\section{TRACER GAS GRADIENT DATA FORM}

$\begin{array}{rlr}\text { Site } & \text { INL HFEF } \\ \text { Date } & \frac{4 / 14 / 2011}{\text { JEF }} \\ \text { Testers } & \frac{83.175}{\mathrm{JE}} \mathrm{in.} \\ \text { Duct Width } & \frac{30.2}{\mathrm{in} .} \\ \text { Duct Depth } & 17.4 \mathrm{ft} 2\end{array}$

Run No. GT-3W

Start/End Time 15:00 / 16:35

Fan Configuration Both Fans

Stack Temp $78 \quad \operatorname{deg} \mathrm{F}$

Injection Point Pipe Nipple

Measurement Loc. West Port - UNDER SHROUDED PROBE

\begin{tabular}{|c|c|c|c|c|c|c|}
\hline \multicolumn{3}{|c|}{ Simultaneous North Port Trial and Points----> } & 1 & 2 & 3 & Mean \\
\hline Port & North Point & W Depth, in. & \multicolumn{4}{|c|}{ ppm SF6 } \\
\hline W & Port 1, 1 & 35.43 & 3.16 & 2.57 & 3.18 & 2.97 \\
\hline W & Port 1, 2 & 35.43 & 2.62 & 3.14 & 2.60 & 2.79 \\
\hline W & Port 1, 3 & 35.43 & 3.33 & 3.20 & 2.65 & 3.06 \\
\hline W & Port 1,4 & 35.43 & 3.00 & 3.11 & 2.29 & 2.80 \\
\hline W & Port 1,5 & 35.43 & 2.21 & 2.73 & 2.78 & 2.57 \\
\hline W & Port 2, 1 & 35.43 & 3.59 & 2.65 & 2.81 & 3.02 \\
\hline W & Port 2, 2 & 35.43 & 3.06 & 2.93 & 3.48 & 3.16 \\
\hline W & Port 2, 3 & 35.43 & 3.64 & 2.79 & 3.25 & 3.23 \\
\hline W & Port 2, 4 & 35.43 & 3.50 & 3.41 & 2.89 & 3.27 \\
\hline W & Port 2, 5 & 35.43 & 3.19 & 3.53 & 2.14 & 2.95 \\
\hline $\mathrm{W}$ & Port 3, 1 & 35.43 & 3.52 & 3.28 & 2.79 & 3.20 \\
\hline W & Port 3, 2 & 35.43 & 2.94 & 2.47 & 3.44 & 2.95 \\
\hline W & Port 3, 3 & 35.43 & 2.97 & 2.59 & 4.08 & 3.21 \\
\hline W & Port 3, 4 & 35.43 & 2.55 & 2.59 & 2.88 & 2.67 \\
\hline W & Port 3, 5 & 35.43 & 2.59 & 2.76 & 3.79 & 3.05 \\
\hline W & Port 4, 1 & 35.43 & 3.30 & 3.21 & 2.62 & 3.04 \\
\hline W & Port 4, 2 & 35.43 & 2.85 & 3.44 & 2.96 & 3.08 \\
\hline W & Port 4, 3 & 35.43 & 3.63 & 3.44 & 2.91 & 3.33 \\
\hline W & Port 4, 4 & 35.43 & 2.74 & 3.06 & 3.23 & 3.01 \\
\hline W & Port 4, 5 & 35.43 & 2.94 & 2.87 & 2.90 & 2.90 \\
\hline & Averages - & 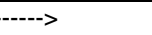 & 3.07 & 2.99 & 2.98 & 3.01 \\
\hline
\end{tabular}

\begin{tabular}{|c|c|c|c|}
\hline \multirow[b]{2}{*}{ Stack Flow (Control Rm) } & Start & Finish & \multirow[b]{2}{*}{$\%$ of 51,900} \\
\hline & N/A & N/A & \\
\hline Stack Flow (KURZ) & -32000 & 32281 & $\mathrm{cfm}$ \\
\hline Tracer tank pressure & 300 & 300 & psig \\
\hline Injection flowmeter & 3.75 & 3.75 & Ipm as $\mathrm{CO} 2$ \\
\hline Stack Temp & 78 & 77 & ${ }^{\circ} \mathrm{F}$ \\
\hline Center Pt. air vel. & 1640 & 1490 & fpm \\
\hline Sampling flowmeter & 10 & 10 & Ipm \\
\hline Ambient pressure & 837 & 838 & mbar \\
\hline Ambient humidity & 30 & 29 & $\mathrm{RH}$ \\
\hline Ambient Temp & 47 & 45 & ${ }^{\circ} \mathrm{F}$ \\
\hline B\&K vapor correction & $\mathrm{Y}$ & $\bar{Y}$ & $\mathrm{Y} / \mathrm{N}$ \\
\hline Back-Gd gas & $9,-.9,-.9,7$ & $38,32,31,24$ & $\mathrm{ppb}$ \\
\hline No. Bk-Gd samples & 4 & & $n$ \\
\hline
\end{tabular}

Notes: $\quad \mathrm{Hi}-\mathrm{Q} \# 1$

Measurements made concurently with a probe under the shrouded probe and at the north ports. At start of test, Port 2, Point 3 was 3.11 vs $3.37 \mathrm{ppm}$ at shroud.

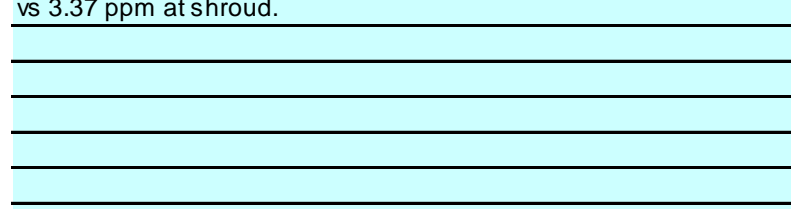

\begin{tabular}{|llr|lr|}
\hline Mean & $\frac{\mathrm{ppm}}{3.01}$ & \multicolumn{1}{c|}{ Deviation } & & \\
Min Point & 3.01 & & \\
Max Point & 2.57 & $-14.6 \%$ & Std. Dev. & 0.20 \\
\cline { 5 - 5 } & 3.33 & $10.4 \%$ & COV as \% & 6.5 \\
\hline
\end{tabular}

Instruments Used:

Cal Due / Check

B\&K 1302 Gas Analyzer SN 1765299

\begin{tabular}{ll}
\hline TSI VelociCalc SN 209060 & $6 / 25 / 2011$ \\
\hline
\end{tabular}

Omega FMA-2606A flowmeter SN $27708 \quad$ N/A

Fisher Weather Station SN 61876141

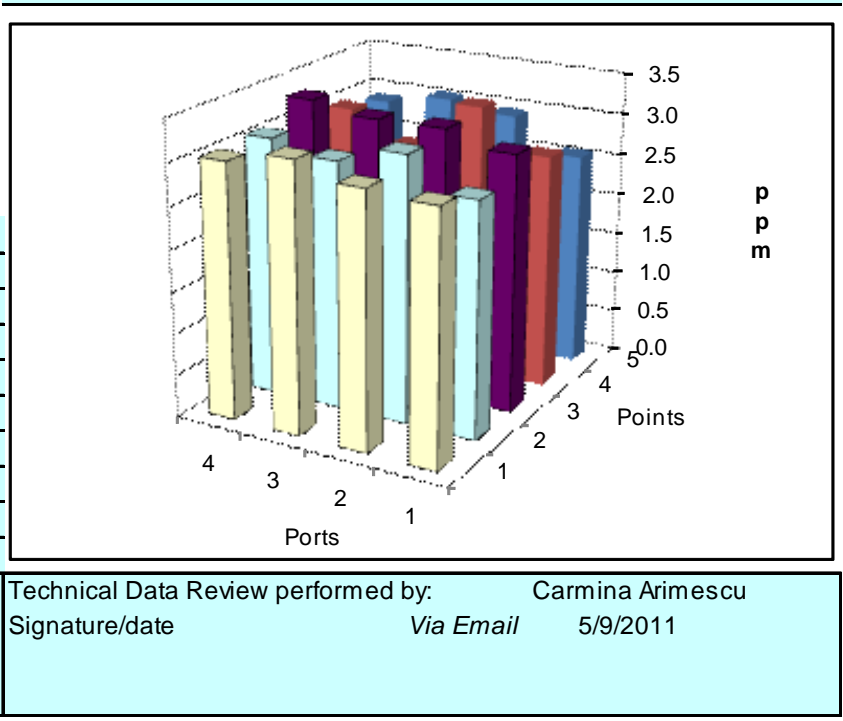




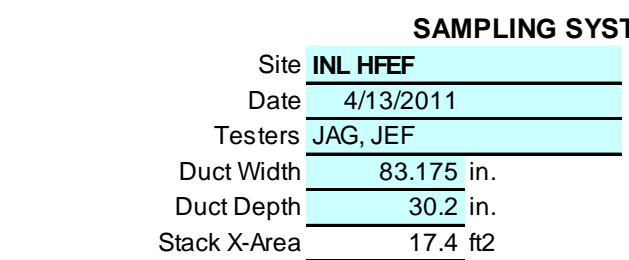

\begin{tabular}{|c|c|c|c|}
\hline General Info & Start & Finish & \multirow{7}{*}{$\begin{array}{l}\% \text { of } 51,900 \\
\text { cfm } \\
\text { psig } \\
\text { Ipm as CO2 } \\
\text { 'F } \\
\text { fpm }\end{array}$} \\
\hline Stack Flow (Control Rm) & N/A & $\mathrm{N} / \mathrm{A}$ & \\
\hline Stack Flow (KURZ) & 32,212 & 31,800 & \\
\hline Tracer tank pressure & 300 & 300 & \\
\hline Injection flowmeter & 3.75 & 3.75 & \\
\hline Stack Temp & 78 & 78 & \\
\hline Center Pt. air vel. & 1410 & 1450 & \\
\hline
\end{tabular}
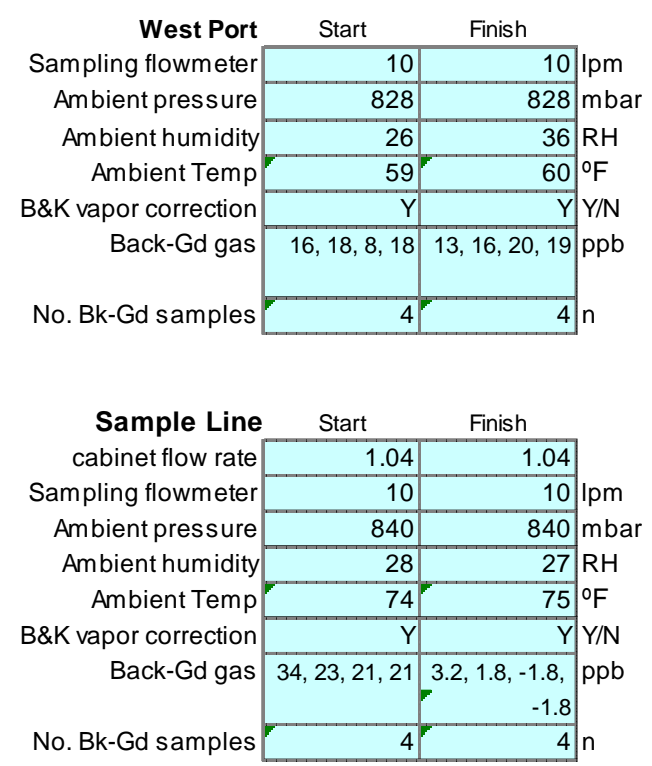

Notes: $\quad$ Shrouded probe is not plumb.

Second floor sampling accomplished with 1/4" tubing connected to the big tee upstream of the CMS2000 box.

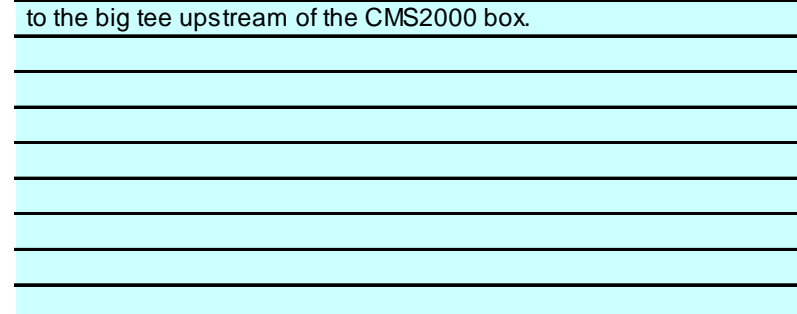

Entries made by: Julia Flaherty

Signature/date On File w/ Original

Run No. BT-1

Start/End Time 13:53/14:40

Fan Configuration Both Fans

Stack Temp

Injection Point Pipe Nipple

Measurement Loc. 2 inches S of Shrouded Probe

\begin{tabular}{|r|c|c|}
\cline { 2 - 3 } \multicolumn{1}{c|}{} & West Port & Sample Line \\
\hline Trial & \multicolumn{2}{c|}{$p p m$ SF6 } \\
\hline 1 & 0.430 & 0.0604 \\
\hline 2 & 0.380 & 0.0538 \\
\hline 3 & 0.313 & 0.0564 \\
\hline 4 & 0.445 & 0.0536 \\
\hline 5 & 0.354 & 0.0797 \\
\hline 6 & 0.423 & 0.0633 \\
\hline 7 & 0.429 & 0.0640 \\
\hline 8 & 0.427 & 0.0590 \\
\hline 9 & 0.483 & 0.0590 \\
\hline 10 & 0.487 & 0.0632 \\
\hline MEAN & 0.417 & 0.061 \\
\hline W/S RATIO: & 6.81 & \multicolumn{1}{|c}{} \\
\hline & \multicolumn{2}{|c|}{}
\end{tabular}

Instruments Used:

Cal Due / Check

West Port B\&K 1302 Gas Analyzer SN 1804888 $4 / 12 / 2011$

Sample Line B\&K 1302 Gas Analyzer SN $1765299 \quad 4 / 12 / 2011$

TSI VelociCalc SN 209060

$6 / 25 / 2011$

Omega FMA-2606A flowmeter SN $27708 \quad$ N/A

West Port Fisher Weather Station SN 61876141

Sample Line Fisher Weather Station SN 90936818

$5 / 17 / 2011$

10/20/2011

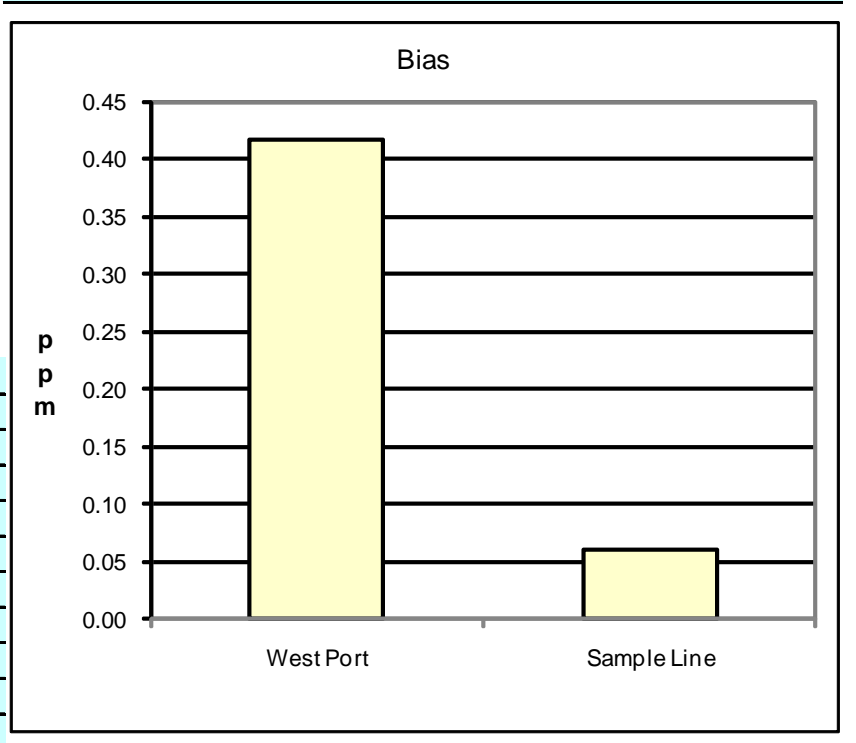

Technical Data Review performed by:

Carmina Arimescu

Signature/date

Via Email 


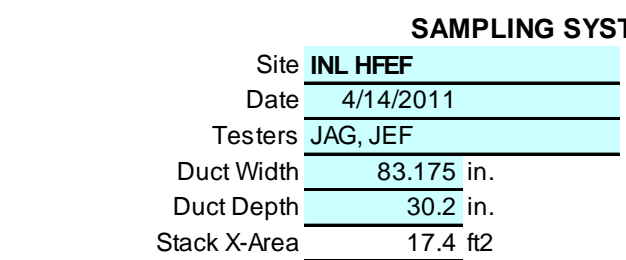

\begin{tabular}{|c|c|c|c|}
\hline General Info & Start & Finish & \\
\hline Stack Flow (Control Rm) & $\mathrm{N} / \mathrm{A}$ & N/A & $\%$ of 51,900 \\
\hline Stack Flow (KURZ) & 32,235 & 24,900 & $\mathrm{cfm}$ \\
\hline Tracer tank pressure & 300 & 300 & psig \\
\hline Injection flowmeter & 3.75 & 3.75 & Ipm as C \\
\hline Stack Temp & 78 & 77 & ${ }^{\circ} \mathrm{F}$ \\
\hline Center Pt. air vel. & 1430 & 1090 & $\mathrm{fpm}$ \\
\hline
\end{tabular}

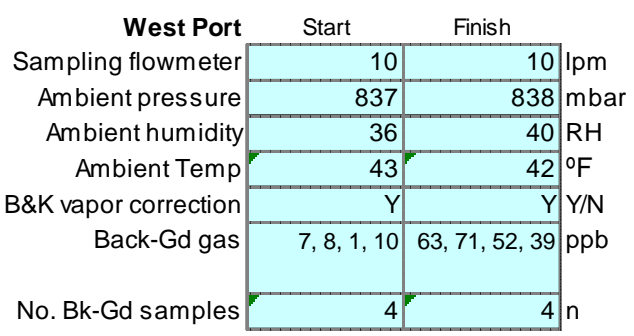

\begin{tabular}{|c|c|c|c|}
\hline Sample Line & Start & Finish & \\
\hline cabinet flow rate & 1.05 & 0.84 & \\
\hline Sampling flowmeter & 10 & 10 & Ipm \\
\hline Ambient pressure & 844 & 844 & $4 \mathrm{mbar}$ \\
\hline Ambient humidity & 26 & 23 & RH \\
\hline Ambient Temp & 75 & 77 & $7{ }^{\circ} \mathrm{F}$ \\
\hline B\&K vapor correction & $\mathrm{Y}$ & $\mathrm{Y}$ & Y Y/N \\
\hline Back-Gd gas & $15,17,16,18$ & $26,31,26,28$ & $8 \mathrm{ppb}$ \\
\hline & 14 & & \\
\hline No. Bk-Gd samples & 5 & & $4 n$ \\
\hline
\end{tabular}

Notes: Started BT-2 on 4/13/2011, but had to quit due to thunder, lightning, rain and snow. Re-start test on 4/14/2011. Our sampling probe is at the same E-W position as the shrouded probe, but 1-2 inches south (in the centerline).

Hi-Q \#2 was used on second floor, Hi-Q \#1 was used on stack.

Observed positive pressure from the big tee.

Prior to run, shrouded probe repositioned to plumb.
Run No. BT-2a

Start/End Time 10:27/11:28

Fan Configuration Both Fans

Stack Temp

Injection Point Pipe Nipple

Measurement Loc. 2 inches S of Shrouded Probe

\begin{tabular}{|c|c|c|}
\hline & West Port & Sample Line \\
\hline Trial & \multicolumn{2}{|c|}{ ppm SF6 } \\
\hline 1 & 0.895 & 0.431 \\
\hline 2 & 0.895 & 0.441 \\
\hline 3 & 1.10 & 0.436 \\
\hline 4 & 0.906 & 0.381 \\
\hline 5 & 0.834 & 0.428 \\
\hline 6 & 0.900 & 0.423 \\
\hline 7 & 1.07 & 0.457 \\
\hline 8 & 1.16 & 0.461 \\
\hline 9 & 0.938 & 0.475 \\
\hline 10 & 1.15 & 0.448 \\
\hline 11 & 1.03 & 0.434 \\
\hline 12 & 1.24 & 0.408 \\
\hline 13 & 1.04 & 0.385 \\
\hline 14 & 0.943 & 0.449 \\
\hline 15 & 1.14 & 0.437 \\
\hline 16 & 1.17 & 0.447 \\
\hline 17 & 0.979 & 0.493 \\
\hline 18 & 1.09 & 0.464 \\
\hline 19 & 0.948 & 0.450 \\
\hline 20 & 1.18 & 0.432 \\
\hline MEAN & 1.03 & 0.44 \\
\hline WIS RATIO: & 2.35 & \\
\hline
\end{tabular}

Instruments Used:

West Port B\&K 1302 Gas Analyzer SN 1765299

Cal Due / Check

$4 / 12 / 2011$

Sample Line B\&K 1302 Gas Analyzer SN 1804888

TSI VelociCalc SN 209060

Omega FMA-2606A flowmeter SN 27708

$4 / 12 / 2011$

West Port Fisher Weather Station SN $61876141 \quad$ N/A

Sample Line Fisher Weather Station SN $90936818 \quad$ 10/20/2011

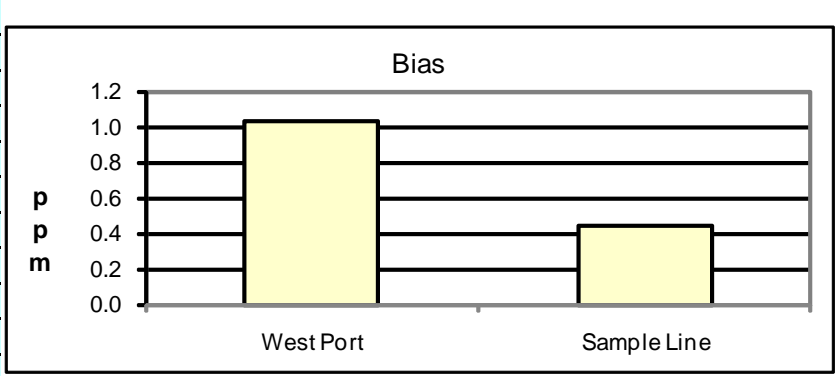

\begin{tabular}{|ll|lcc|}
\hline $\begin{array}{l}\text { Entries made by: } \\
\text { Signature/date }\end{array}$ & $\begin{array}{l}\text { Julia Flaherty } \\
\text { On File } w / \text { Original }\end{array}$ & $4 / 14 / 2011$ & $\begin{array}{l}\text { Technical Data Review performed by: } \\
\text { Signature/date }\end{array}$ & Carmina Arimescu \\
& & & $5 / 17 / 2011$ \\
& & \\
\end{tabular}




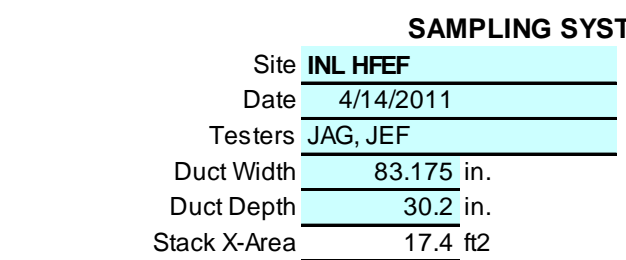

\begin{tabular}{|c|c|c|c|}
\hline General Info & Start & Finish & \\
\hline Stack Flow (Control Rm) & $\mathrm{N} / \mathrm{A}$ & N/A & $\%$ of 51,900 \\
\hline Stack Flow (KURZ) & 32,235 & 24,900 & $\mathrm{cfm}$ \\
\hline Tracer tank pressure & 300 & 300 & psig \\
\hline Injection flowmeter & 3.75 & 3.75 & Ipm as C \\
\hline Stack Temp & 78 & 77 & ${ }^{\circ} \mathrm{F}$ \\
\hline Center Pt. air vel. & 1430 & 1090 & fpm \\
\hline
\end{tabular}

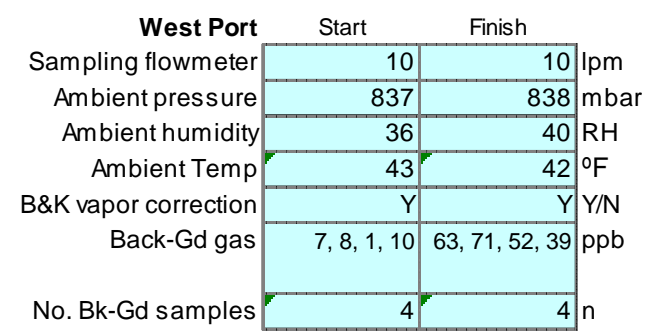

\begin{tabular}{|c|c|c|c|}
\hline Sample Line & Start & Finish & \\
\hline cabinet flow rate & 1.05 & 0.84 & \\
\hline Sampling flowmeter & 10 & 10 & $\mathrm{Ipm}$ \\
\hline Ambient pressure & 844 & 844 & $4 \mathrm{mbar}$ \\
\hline Ambient humidity & 26 & 23 & RH \\
\hline Ambient Temp & 75 & 77 & $7^{\circ} \mathrm{F}$ \\
\hline B\&K vapor correction & $\mathrm{Y}$ & $Y$ & $\mathrm{Y} Y / \mathrm{N}$ \\
\hline Back-Gd gas & $15,17,16,18$ & $26,32,26,28$ & $8 \mathrm{ppb}$ \\
\hline No. Bk-Gd samples & 5 & & $4 \mathrm{n}$ \\
\hline
\end{tabular}

Notes: Started BT-2 on 4/13/2011, but had to quit due to thunder, lightning, rain and snow. Re-start test on 4/14/2011. Our sampling probe is at the same E-W position as the shrouded probe, but 1-2 inches south (in the centerline).

BT-2b tested the effect of removing the in-line filter holder. For the first 10 measurements, the downstairs system had no filter holder. For the second 10 measurements, both systems had no filter holder.

At end of testing, discovered that filter holder on the scaffold did not contain a filter.

Entries made by.

Julia Flaherty

On File w/ Original

Signature/date
Run No. BT-2b

Start/End Time 10:27/11:28

Fan Configuration Both Fans

Stack Temp

Injection Point Pipe Nipple

Measurement Loc. 2 inches S of Shrouded Probe

\begin{tabular}{|c|c|c|}
\hline & West Port & Sample Line \\
\hline Trial & \multicolumn{2}{|c|}{ ppm SF6 } \\
\hline 1 & 1.22 & 1.06 \\
\hline 2 & 1.30 & 1.03 \\
\hline 3 & 0.996 & 0.903 \\
\hline 4 & 1.01 & 0.927 \\
\hline 5 & 1.30 & 1.13 \\
\hline 6 & 1.20 & 0.997 \\
\hline 7 & 1.11 & 0.887 \\
\hline 8 & 1.30 & 0.937 \\
\hline 9 & 1.13 & 0.989 \\
\hline 10 & 1.27 & 0.984 \\
\hline 11 & 1.08 & 1.06 \\
\hline 12 & 1.67 & 0.988 \\
\hline 13 & 1.86 & 0.930 \\
\hline 14 & 1.90 & 0.962 \\
\hline 15 & 1.87 & 0.974 \\
\hline 16 & 1.96 & 0.974 \\
\hline 17 & 1.96 & 0.921 \\
\hline 18 & 2.17 & 1.01 \\
\hline 19 & 2.10 & 1.09 \\
\hline 20 & 2.23 & 0.974 \\
\hline MEAN & 1.53 & 0.99 \\
\hline WIS RATIO: & 1.55 & \\
\hline
\end{tabular}

Instruments Used:

Cal Due / Check

West Port B\&K 1302 Gas Analyzer SN 1765299

$4 / 12 / 2011$

Sample Line B\&K 1302 Gas Analyzer SN $1804888 \quad 4 / 12 / 2011$

TSI VelociCalc SN 209060

Omega FMA-2606A flowmeter SN 27708

$6 / 25 / 2011$

West Port Fisher Weather Station SN $61876141 \quad 5 / 17 / 2011$

Sample Line Fisher Weather Station SN $90936818 \quad 10 / 20 / 2011$

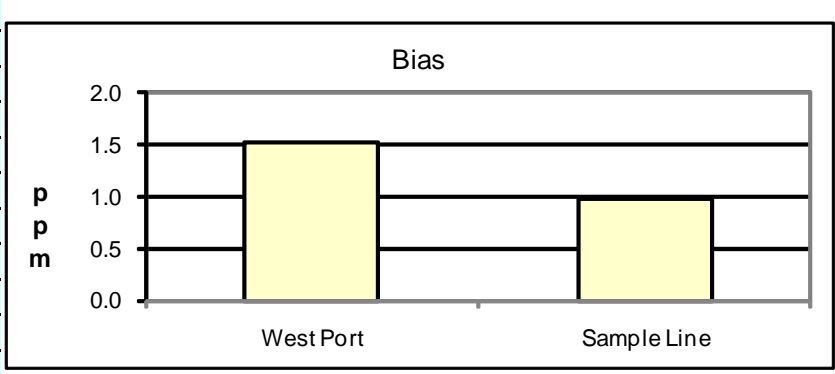

4/14/2011 Technical Data Review performed by:

Signature/date

Via Email

Carmina Arimescu

5/17/2011 


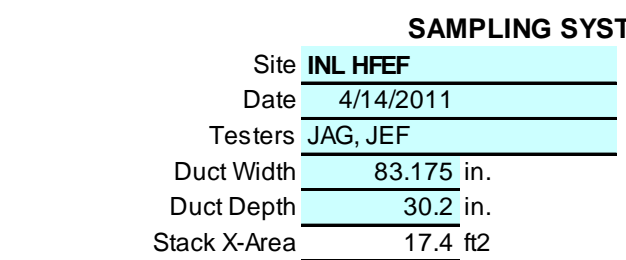

\begin{tabular}{|c|c|c|c|}
\hline General Info & Start & Finish & \\
\hline Stack Flow (Control Rm) & $\mathrm{N} / \mathrm{A}$ & N/A & $\%$ of 51,900 \\
\hline Stack Flow (KURZ) & 32,516 & 32,700 & $\mathrm{cfm}$ \\
\hline Tracer tank pressure & 300 & 300 & psig \\
\hline Injection flowmeter & 3.75 & 3.75 & Ipm as C \\
\hline Stack Temp & 78 & 78 & ${ }^{\circ} \mathrm{F}$ \\
\hline Center Pt. air vel. & 1620 & 1640 & fpm \\
\hline
\end{tabular}
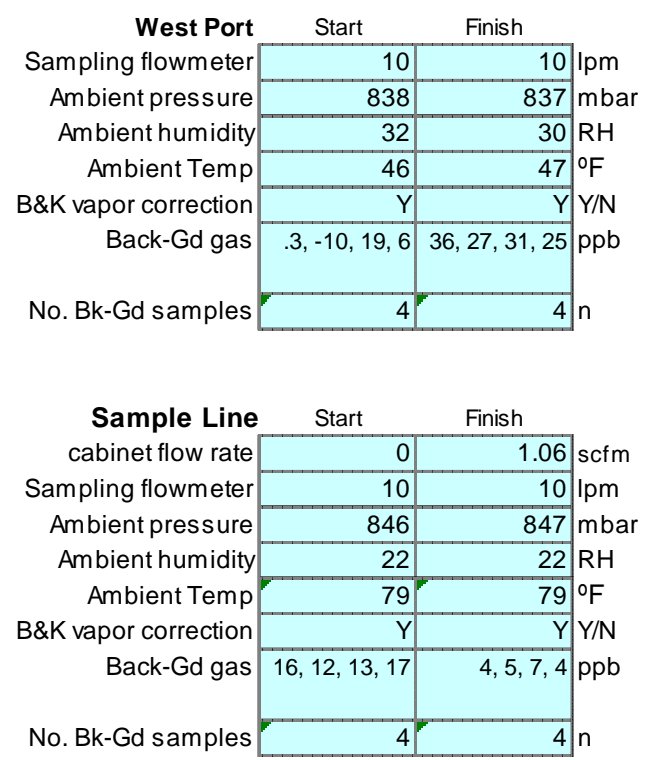

Notes: Our probe is at the same E-W position as the shrouded probe, and is about 1.5 inches south for the first 10 readings. $1650 \mathrm{fpm}, 79 \mathrm{deg} F$ in stack after sampling.

14:13 back up scaffold to fill tedlar bag (sample line has been done). $\sim 8$ min to fill.

$\sim 50$ deg $\mathrm{F}$ in the shelter box.

At start, sampling cablinet flow is off and ball valve is closed.

For readings $11-20$, our probe was positioned directly below the shrouded probe nozzle.

Hi-Q \#2 used on 2nd floor, Hi-Q \#1 used on scaffold.

\begin{tabular}{|ll|}
\hline Entries made by: & Julia Flaherty \\
Signature/date & On File w/Original \\
& \\
& \\
\hline
\end{tabular}

\section{BIAS DATA FORM}

Run No. BT-3a

Start/End Time 12:50/14:29

Fan Configuration Both Fans

Stack Temp

$78 \quad \operatorname{deg} \mathrm{F}$

Injection Point Pipe Nipple

Measurement Loc. 2 inches S of / Under Shrouded Probe

\begin{tabular}{|r|c|c|}
\cline { 2 - 3 } \multicolumn{1}{c|}{} & West Port & Sample Line \\
\hline Trial & \multicolumn{2}{c|}{ ppm SF6 } \\
\hline 1 & 2.08 & 0.955 \\
\hline 2 & 2.06 & 0.968 \\
\hline 3 & 2.92 & 0.984 \\
\hline 4 & 2.39 & 0.979 \\
\hline 5 & 2.86 & 0.938 \\
\hline 6 & 2.81 & 0.979 \\
\hline 7 & 3.03 & 0.993 \\
\hline 8 & 2.34 & 0.982 \\
\hline 9 & 2.44 & 0.974 \\
\hline 10 & 3.37 & 0.947 \\
\hline 11 & 2.91 & 0.931 \\
\hline 12 & 3.30 & 0.926 \\
\hline 13 & 3.53 & 0.920 \\
\hline 14 & 3.46 & 0.932 \\
\hline 15 & 3.46 & 0.941 \\
\hline 16 & 3.13 & 0.940 \\
\hline 17 & 3.53 & 0.922 \\
\hline 18 & 3.54 & 0.948 \\
\hline 19 & 3.03 & 0.934 \\
\hline 20 & 3.73 & 0.985 \\
\hline MEAN & 3.00 & 0.95 \\
\hline W/S RATIO: & 3.14 & \\
\hline & \multicolumn{2}{|c}{} \\
\hline & & \\
\hline 15 &
\end{tabular}

Instruments Used:

Cal Due / Check

West Port B\&K 1302 Gas Analyzer SN 1765299

$4 / 12 / 2011$

Sample Line B\&K 1302 Gas Analyzer SN $1804888 \quad 4 / 12 / 2011$

TSI VelociCalc SN 209060

Omega FMA-2606A flowmeter SN 27708

$6 / 25 / 2011$

West Port Fisher Weather Station SN $61876141 \quad$ 5/17/2011

Sample Line Fisher Weather Station SN 90936818

\section{Samp}

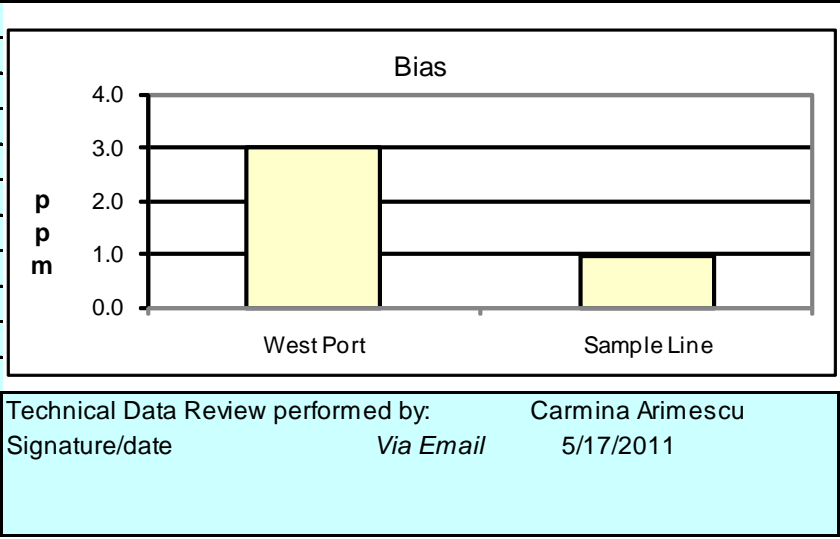




\begin{tabular}{|c|c|c|c|c|c|c|}
\hline \multicolumn{7}{|c|}{ SAMPLING SYSTEM GAS BIAS DATA FORM } \\
\hline \multicolumn{3}{|c|}{ Site INL HFF } & \multicolumn{4}{|c|}{ Run No. BT-3b } \\
\hline \multirow{2}{*}{$\begin{array}{r}\text { Date } \\
\text { Testers }\end{array}$} & 4/14/2011 & & \multicolumn{4}{|c|}{ Start/End Time 15:00 } \\
\hline & \multicolumn{2}{|l|}{ JAG, JEF } & \multicolumn{4}{|c|}{ Fan Configuration Both Fans } \\
\hline Duct Width & \multicolumn{2}{|c|}{$83.175 \mathrm{in.}$} & \multicolumn{2}{|r|}{ Stack Temp } & 78 & $\operatorname{deg} \mathrm{F}$ \\
\hline Duct Depth & \multicolumn{2}{|c|}{$30.2 \mathrm{in}}$. & \multicolumn{4}{|c|}{ Injection Point Pipe Nipple } \\
\hline Stack X-Area & \multicolumn{2}{|c|}{$17.4 \mathrm{ft} 2$} & \multirow{2}{*}{\multicolumn{2}{|c|}{ Measurement Loc. }} & Under Shrou & ded Probe \\
\hline \multirow{3}{*}{$\begin{array}{r}\text { General Info } \\
\text { Stack Flow (Control Rm) } \\
\text { Stack Flow (KURZ) }\end{array}$} & \multicolumn{2}{|r|}{ Finish } & & & West Port & Sample Line \\
\hline & $\mathrm{N} / \mathrm{A}$ & $\mathrm{N} / \mathrm{A}$ & \multirow{5}{*}{$\begin{array}{l}\% \text { of } 51,900 \\
\mathrm{cfm} \\
\mathrm{psig} \\
\text { Ipm as CO2 } \\
{ }^{\circ} \mathrm{F}\end{array}$} & Trial & \multicolumn{2}{|c|}{ ppm SF6 } \\
\hline & 32,516 & 32,700 & & 1 & 5.76 & 5.76 \\
\hline \multirow{6}{*}{$\begin{array}{r}\text { Tracer tank pressure } \\
\text { Injection flowmeter } \\
\text { Stack Temp } \\
\text { Center Pt. air vel. }\end{array}$} & 300 & 300 & & 2 & 5.75 & 5.78 \\
\hline & 3.75 & 3.75 & & 3 & 5.75 & 5.79 \\
\hline & 78 & 78 & & 4 & 5.73 & 5.77 \\
\hline & 1620 & 1640 & fpm & 5 & 5.74 & 5.77 \\
\hline & & & & 6 & 5.75 & 5.79 \\
\hline & & & & 7 & 5.75 & 5.78 \\
\hline West Port & Start & Finish & & 8 & 5.72 & 5.78 \\
\hline Sampling flowmeter & 10 & 10 & Ipm & 9 & 5.70 & 5.78 \\
\hline Ambient pressure & 838 & 837 & mbar & 10 & 5.72 & 5.79 \\
\hline Ambient humidity & 32 & 30 & $\mathrm{RH}$ & 11 & 5.73 & 5.71 \\
\hline Ambient Temp & 46 & 47 & ${ }^{\circ} \mathrm{F}$ & 12 & 5.71 & 5.69 \\
\hline B\&K vapor correction & $\mathrm{Y}$ & $\mathrm{Y}$ & Y/N & 13 & 5.71 & 5.70 \\
\hline Back-Gd gas & $.3,-10,19,6$ & $36,27,31,25$ & ppb & MEAN & 5.73 & 5.76 \\
\hline & & & & WIS RATIO: & 1.00 & \\
\hline No. Bk-Gd samples & 4 & 4 & $n$ & & & \\
\hline
\end{tabular}

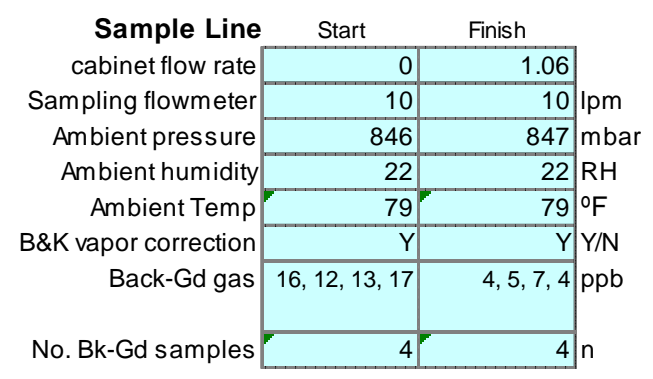

Notes: At the end of BT-3, tedlar bags were filled in place of real-time analysis using the B\&K analyzer. This data sheet contains the results of the analysis of the contents of the Tedlar bags using two different B\&K analyzers.

Tedlar bag analysis was conducted with B\&K SN 1804888 for trial 1-8. Tedlar bag analysis was conducted with B\&K SN 1788615 for trial 9-13.

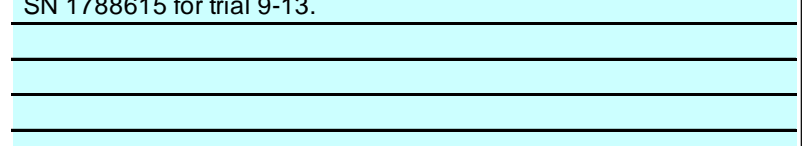

\begin{tabular}{|lll|}
\hline $\begin{array}{l}\text { Entries made by: } \\
\text { Signature/date }\end{array}$ & John Glissmeyer & $4 / 14 / 2011$ \\
& On File w/ Original & \\
& & \\
\end{tabular}

Instruments Used:

B\&K 1302 Gas Analyzer SN 1804888

Cal Due I Check

B\&K 1302 Gas Analyzer SN $1788615 \quad 4 / 13 / 2011$

TSI VelociCalc SN $209060 \quad 6 / 25 / 2011$

Omega FMA-2606A flowmeter SN $27708 \quad$ N/A

West Port Fisher Weather Station SN $61876141 \quad$ 5/17/2011

Sample Line Fisher Weather Station SN $90936818 \quad 10 / 20 / 2011$

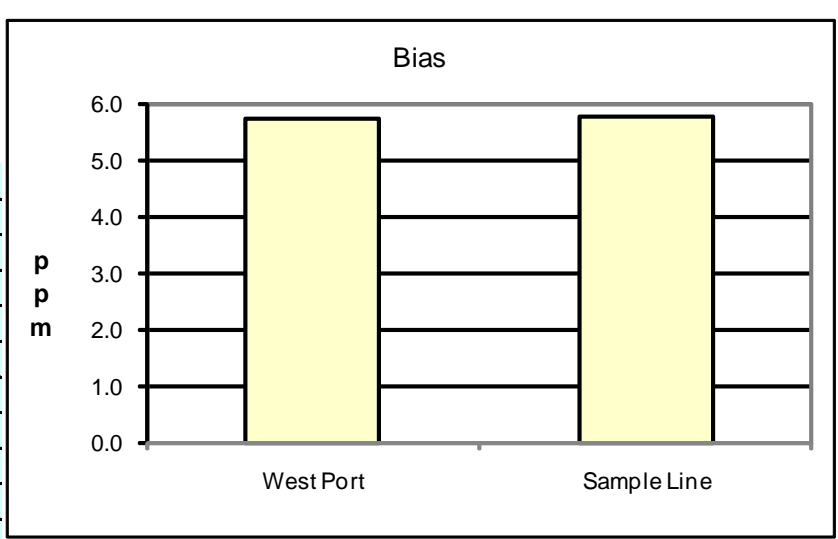

Technical Data Review performed by:

Signature/date

Via Email

Carmina Arimescu

$5 / 17 / 2011$ 


\section{SULFUR HEXAFLUORIDE GAS INSTRUMENT CALIBRATION}

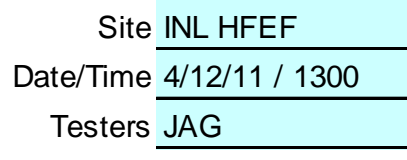

$\begin{aligned} & \text { Instrument } \text { B\&K Model } 1302 \\ & \text { Serial No. } 1765299 \\ & \text { Property No. WD17210 }\end{aligned}$

Setup: $\quad 6.33 \mathrm{ft} \quad$ B\&K sample inlet tube length

836 mbar station pressure

64 deg $\mathrm{F}$ ambient temp analyzer corrects to 20 deg $\mathrm{C}$

33 percent $\mathrm{RH}$

\section{Pre-Test background, ppb \\ Not compensating for water vapor, monitoring task 2}

85.4, 76.6, 76.9, 78.7, 71.9

Compensating for water vapor, monitoring task 1

$65.1,66.5,58.8,65.7,61.2$

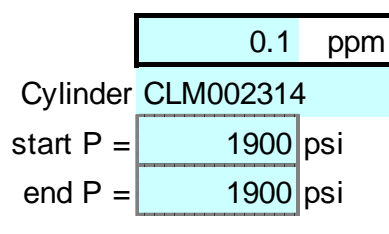

B\&K

Calibration

readings: (ppm)

Compensating for water vapor

\begin{tabular}{|r|}
\hline 0.108 \\
\hline 0.114 \\
\hline 0.109 \\
\hline 0.112 \\
\hline 0.0992 \\
\hline
\end{tabular}

Not compensating for water vapor

\begin{tabular}{|l|}
\hline 0.110 \\
\hline 0.111 \\
\hline 0.113 \\
\hline 0.111 \\
\hline 0.110 \\
\hline $\mathbf{0 . 1 1 0}=$ avg \\
$\mathbf{1 . 0 9 7}=$ avg/standard
\end{tabular}

Standards Used:

\begin{tabular}{|c|c|c|c|c|}
\hline Standards Used: & & \multicolumn{2}{|c|}{ Expiration date: } & \\
\hline Scott Specialty Gas & 0.1 ppm SF6 in air, CLM002314 & \multicolumn{2}{|c|}{$3 / 3 / 2012$} & \\
\hline Scott Specialty Gas & 5.01 ppm SF6 in air, CAL011887 & \multicolumn{2}{|c|}{$3 / 3 / 2013$} & \\
\hline \multicolumn{2}{|c|}{ Fisher Scientific SN 61876141 ID\# WSFI1-0005 } & \multicolumn{2}{|c|}{$5 / 17 / 2011$} & \\
\hline $\begin{array}{l}\text { Entries made by: } \\
\text { Signature/date }\end{array}$ & $\begin{array}{l}\text { ohn Glissmeyer } \\
\text { On File with Original }\end{array}$ & $\begin{array}{l}\text { Technical Data } \\
\text { Signature/date }\end{array}$ & $\begin{array}{l}\text { erformed by: } \\
\text { Carmina Arimescu } \\
\text { Via Email }\end{array}$ & $5 / 9 / 2011$ \\
\hline
\end{tabular}

B\&K

Calibration

readings: (ppm)

Compensating for water vapor

\begin{tabular}{|r|}
\hline 5.52 \\
\hline 5.50 \\
\hline 5.50 \\
\hline 5.51 \\
\hline 5.49 \\
\hline
\end{tabular}

Not compensating for water vapor

\begin{tabular}{|r|}
\hline 5.47 \\
\hline 5.46 \\
\hline 5.46 \\
\hline 5.47 \\
\hline 5.46 \\
\hline $5.48=$ avg \\
$1.095=$ avg/standard
\end{tabular}

Expiration date:

Cylinder CAL011887

start $P=2000$ psi

end $P=2000$ psi 


\section{SULFUR HEXAFLUORIDE GAS INSTRUMENT CALIBRATION}

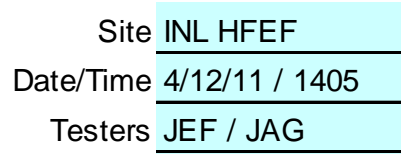

$\begin{aligned} & \text { Instrument } \text { B\&K Model } 1302 \\ & \text { Serial No. } 1804888 \\ & \text { Property No. WD54623 }\end{aligned}$

Setup: $6.33 \mathrm{ft} \quad$ B\&K sample inlet tube length 836 mbar station pressure 67 deg $\mathrm{F}$ ambient temp analyzer corrects to 20 deg $\mathrm{C}$ 30 percent $\mathrm{RH}$

Pre-Test background, ppb

Not compensating for water vapor, monitoring task 2

59.9, 58.4, 57.8, 58.5, 53.3

Compensating for water vapor, monitoring task 1

$34.8,32.4,32.4,32.2,29.0$

\section{$0.1 \mathrm{ppm}$}

Cylinder CLM002314

start $P=1900$ psi

end $P=1800$ psi

B\&K

Calibration

readings: (ppm)

Compensating for water vapor

\begin{tabular}{|r|}
\hline 0.107 \\
\hline 0.107 \\
\hline 0.110 \\
\hline 0.110 \\
\hline 0.110 \\
\hline
\end{tabular}

Not compensating for water vapor

\begin{tabular}{|l|}
\hline 0.108 \\
\hline 0.106 \\
\hline 0.113 \\
\hline 0.107 \\
\hline 0.107 \\
\hline $\mathbf{0 . 1 0 9}$ \\
$\mathbf{1 . 0 8 5}$
\end{tabular}

Standards Used:

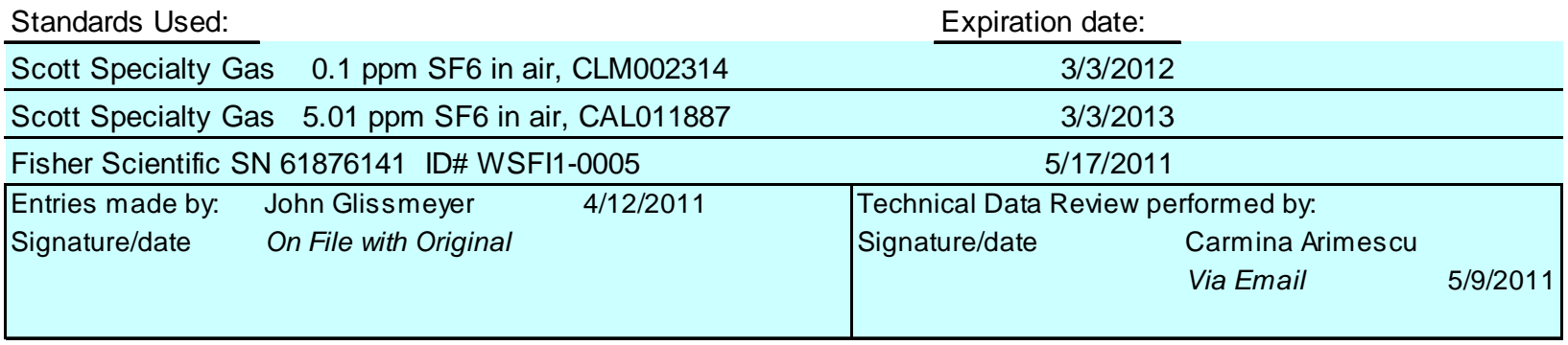

B\&K

Calibration readings: (ppm)

Compensating for water vapor

\begin{tabular}{|r|}
\hline 5.37 \\
\hline 5.37 \\
\hline 5.19 \\
\hline 5.20 \\
\hline 5.17 \\
\hline
\end{tabular}

Not compensating for water vapor

\begin{tabular}{|r|}
\hline 5.15 \\
\hline 5.12 \\
\hline 5.15 \\
\hline 5.27 \\
\hline 5.34 \\
\hline $\mathbf{5 . 2 3}$ \\
$\mathbf{1 . 0 4 5}=\mathrm{avg}$ \\
\end{tabular}

Expiration date:

Cylinder CAL011887

start $P=2000$ psi

end $P=1900$ psi 


\section{SULFUR HEXAFLUORIDE GAS INSTRUMENT CALIBRATION}

$\begin{aligned} \text { Site } & \text { INL HFEF } \\ \text { Date/Time } & \text { 4/13/2011 } \\ \text { Testers JAG } & \text { JA }\end{aligned}$

\author{
Instrument B\&K Model 1302 \\ Serial No. \\ 1788615 \\ Property No. WD54624
}

Setup: $7.5 \mathrm{ft} \quad$ B\&K sample inlet tube length

840 mbar station pressure

63 deg $\mathrm{F}$ ambient temp analyzer corrects to 20 deg $\mathrm{C}$

33 percent $\mathrm{RH}$

\section{Pre-Test background, ppb}

Not compensating for water vapor, monitoring task 2

14.6, 10.8, 13.4, 9.05, 7.48

Compensating for water vapor, monitoring task 1

$48.6,37.7,35.3,31.0,33.6$

\section{$0.1 \mathrm{ppm}$}

Cylinder CLM002314

start $P=1800$ psi

end $P=1700$ psi

B\&K

Calibration

readings: (ppm)

Compensating for water vapor

\begin{tabular}{|r|}
\hline 0.108 \\
\hline 0.102 \\
\hline 0.104 \\
\hline 0.101 \\
\hline 0.103 \\
\hline
\end{tabular}

Not compensating for water vapor

\begin{tabular}{|l|}
\hline 0.103 \\
\hline 0.102 \\
\hline 0.102 \\
\hline 0.102 \\
\hline 0.102 \\
\hline $\mathbf{0 . 1 0 3}=$ avg \\
$\mathbf{1 . 0 2 9}=$ avg/standard
\end{tabular}

Standards Used:

\begin{tabular}{|c|c|c|c|c|}
\hline Standards Used: & & \multicolumn{2}{|c|}{ Expiration date: } & \\
\hline Scott Specialty Gas & 0.1 ppm SF6 in air, CLM002314 & \multicolumn{2}{|c|}{$3 / 3 / 2012$} & \\
\hline Scott Specialty Gas & 5.01 ppm SF6 in air, CAL011887 & \multicolumn{2}{|c|}{$3 / 3 / 2013$} & \\
\hline \multicolumn{2}{|c|}{ Fisher Scientific SN 90936818 ID\# WSFI1-0006 } & \multicolumn{2}{|c|}{$10 / 20 / 2011$} & \\
\hline $\begin{array}{l}\text { Entries made by: } \\
\text { Signature/date }\end{array}$ & $\begin{array}{l}\text { John Glissmeyer } \\
\text { On File with Original }\end{array}$ & \multicolumn{3}{|c|}{ 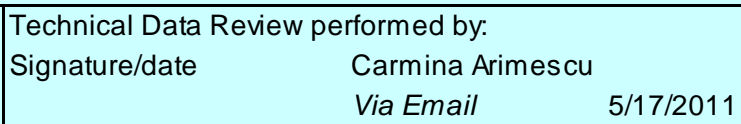 } \\
\hline
\end{tabular}

B\&K

Calibration

readings: (ppm)

Compensating for water vapor

\begin{tabular}{|r|}
\hline 5.32 \\
\hline 5.35 \\
\hline 5.34 \\
\hline 5.33 \\
\hline 5.32 \\
\hline
\end{tabular}

Not compensating for water vapor

\begin{tabular}{|r|}
\hline 5.42 \\
\hline 5.42 \\
\hline 5.20 \\
\hline 5.35 \\
\hline 5.41 \\
\hline $5.35=$ avg \\
$1.067=$ avg/standard
\end{tabular}

Cylinder CAL011887

$\begin{aligned} \text { start } P & =1800 \text { psi } \\ \text { end } P & =1800 \text { psi }\end{aligned}$

$5.01 \mathrm{ppm}$ si

$1800 \mathrm{psi}$ 


\section{SULFUR HEXAFLUORIDE GAS INSTRUMENT CALIBRATION}

$\begin{aligned} \text { Site } & \text { INL HFEF } \\ \text { Date/Time } & \frac{4 / 14 / 2011}{\text { Testers JEF / JAG }}\end{aligned}$

$\begin{aligned} & \text { Instrument } \text { B\&K Model } 1302 \\ & \text { Serial No. } 1765299 \\ & \text { Property No. WD17210 }\end{aligned}$
Setup: $\quad 7.5 \mathrm{ft} \quad$ B\&K sample inlet tube length
848 mbar station pressure
66.2 deg F ambient temp analyzer corrects to 20 deg C
24 percent $\mathrm{RH}$
Pre-Test background, ppb
Not compensating for water vapor, monitoring task 2
$33,35,28,24,24$
Compensating for water vapor, monitoring task 1
$64,52,34,35,35$

\begin{tabular}{|c|c|c|}
\hline & 0.1 & $\mathrm{pp}$ \\
\hline \multicolumn{3}{|c|}{ Cylinder CLM002314 } \\
\hline start $\mathrm{P}=$ & 1800 & psi \\
\hline end $\mathrm{P}=$ & 1800 & psi \\
\hline
\end{tabular}

B\&K

Calibration

readings: (ppm)

Compensating for water vapor

\begin{tabular}{|r|}
\hline 0.106 \\
\hline 0.107 \\
\hline 0.102 \\
\hline 0.102 \\
\hline 0.1030 \\
\hline
\end{tabular}

Not compensating for water vapor

\begin{tabular}{|r|}
\hline 0.101 \\
\hline 0.107 \\
\hline 0.103 \\
\hline 0.102 \\
\hline 0.103 \\
\hline $\mathbf{0 . 1 0 4}=\mathrm{avg}$ \\
$\mathbf{1 . 0 3 6}=\mathrm{avg} / \mathrm{standard}$
\end{tabular}

Standards Used:

\begin{tabular}{|c|c|c|c|c|}
\hline Standards Used: & & \multicolumn{2}{|c|}{ Expiration date: } & \\
\hline Scott Specialty Gas & 0.1 ppm SF6 in air, CLM002314 & \multicolumn{2}{|c|}{$3 / 3 / 2012$} & \\
\hline Scott Specialty Gas & 5.01 ppm SF6 in air, CAL011887 & \multicolumn{2}{|c|}{$3 / 3 / 2013$} & \\
\hline \multicolumn{2}{|c|}{ Fisher Scientific SN 90936818} & \multicolumn{2}{|c|}{$10 / 20 / 2011$} & \\
\hline $\begin{array}{ll}\text { Entries made by: } & \mathrm{J} \\
\text { Signature/date } & \mathrm{C}\end{array}$ & $\begin{array}{l}\text { John Glissmeyer } \\
\text { On File with Original }\end{array}$ & $\begin{array}{l}\text { Technical Data } \\
\text { Signature/date }\end{array}$ & $\begin{array}{l}\text { Carformed by: } \\
\text { Via Email }\end{array}$ & $5 / 9 / 2011$ \\
\hline
\end{tabular}

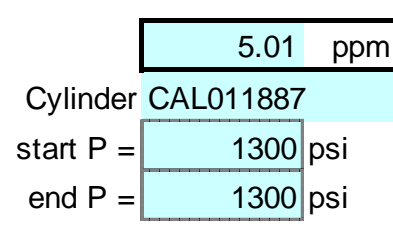

$B \& K$

Calibration

readings: (ppm)

Compensating for water vapor

\begin{tabular}{|r|}
\hline 5.16 \\
\hline 5.17 \\
\hline 5.16 \\
\hline 5.15 \\
\hline 5.16 \\
\hline
\end{tabular}

Not compensating for water vapor

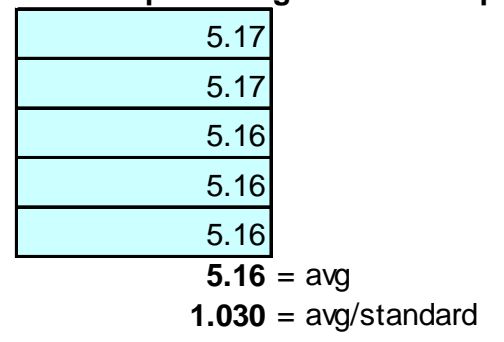

\begin{tabular}{|r|}
\hline 5.17 \\
\hline 5.17 \\
\hline 5.16 \\
\hline 5.16 \\
\hline 5.16 \\
\hline $\mathbf{5 . 1 6}=$ avg \\
$1.030=$ avg/standard
\end{tabular}

Expiration date: 


\section{SULFUR HEXAFLUORIDE GAS INSTRUMENT CALIBRATION}

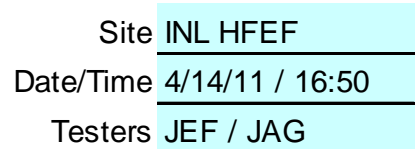

Setup: $7.5 \mathrm{ft} \quad$ B\&K sample inlet tube length

848 mbar station pressure

66.2 deg $\mathrm{F}$ ambient temp analyzer corrects to 20 deg $\mathrm{C}$

24 percent $\mathrm{RH}$

\section{Pre-Test background, ppb}

Not compensating for water vapor, monitoring task 2

21.0, 19.7, 18.9, 8.95, 22.1

Compensating for water vapor, monitoring task 1

$12.0,7.35,8.97,7.00,5.34$

\section{$0.1 \mathrm{ppm}$}

Cylinder CLM002314

start $P=1700$ psi

end $P=1700$ psi

$B \& K$

Calibration

readings: (ppm)

Compensating for water vapor

\begin{tabular}{|r|}
\hline 0.113 \\
\hline 0.110 \\
\hline 0.108 \\
\hline 0.109 \\
\hline 0.108 \\
\hline
\end{tabular}

Not compensating for water vapor

\begin{tabular}{|r|}
\hline 0.111 \\
\hline 0.109 \\
\hline 0.108 \\
\hline 0.106 \\
\hline 0.108 \\
\hline $\mathbf{0 . 1 0 9}=$ avg \\
$1.09=$ avg/standard
\end{tabular}

Standards Used:

\begin{tabular}{|c|c|c|c|c|}
\hline Standards Used: & & \multicolumn{2}{|c|}{ Expiration date: } & \\
\hline Scott Specialty Gas & 0.1 ppm SF6 in air, CLM002314 & \multicolumn{2}{|c|}{$3 / 3 / 2012$} & \\
\hline Scott Specialty Gas & 5.01 ppm SF6 in air, CAL011887 & \multicolumn{2}{|c|}{$3 / 3 / 2013$} & \\
\hline \multicolumn{2}{|c|}{ Fisher Scientific SN 90936818} & \multicolumn{2}{|c|}{$10 / 20 / 2011$} & \\
\hline $\begin{array}{l}\text { Entries made by: } \\
\text { Signature/date }\end{array}$ & $\begin{array}{l}\text { John Glissmeyer } \\
\text { On File with Original }\end{array}$ & \multicolumn{3}{|c|}{$\begin{array}{|lll|}\text { Technical Data Review performed by: } & \\
\text { Signature/date } & \text { Carmina Arimescu } & \\
& \text { Via Email } & 5 / 9 / 2011\end{array}$} \\
\hline
\end{tabular}

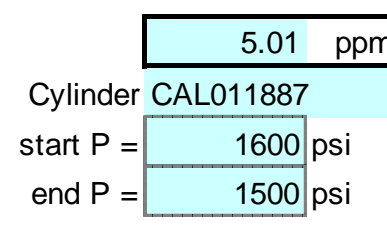

B\&K

Calibration

readings: (ppm)

Compensating for water vapor

\begin{tabular}{|r|}
\hline 5.13 \\
\hline 5.15 \\
\hline 5.12 \\
\hline 5.14 \\
\hline 5.13 \\
\hline
\end{tabular}

Not compensating for water vapor

\begin{tabular}{|r|}
\hline 5.13 \\
\hline 5.11 \\
\hline 5.18 \\
\hline 5.14 \\
\hline 5.16 \\
\hline $5.14=$ avg \\
$1.026=$ avg/standard
\end{tabular}

Expiration date:
Instrument B\&K Model 1302

Serial No. 1804888

Property No. WD54623 


\section{SULFUR HEXAFLUORIDE GAS INSTRUMENT CALIBRATION}

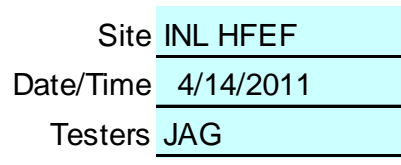

$\begin{aligned} & \text { Instrument } \text { B\&K Model } 1302 \\ & \text { Serial No. } 1788615 \\ & \text { Property No. WD54624 }\end{aligned}$

Setup: $\quad 7.5 \mathrm{ft} \quad$ B\&K sample inlet tube length

848 mbar station pressure

64 deg $\mathrm{F}$ ambient temp analyzer corrects to 20 deg C

26 percent $\mathrm{RH}$

\section{Pre-Test background, ppb \\ Not compensating for water vapor, monitoring task 2}

$13,17,12,18,13$

Compensating for water vapor, monitoring task 1

$16,14,7,7,<0$

\section{$0.1 \mathrm{ppm}$}

Cylinder CLM002314

$\begin{aligned} \text { start } P & =1800 \text { psi } \\ \text { end } P & =1800 \text { psi }\end{aligned}$

B\&K

Calibration

readings: (ppm)

Compensating for water vapor

\begin{tabular}{|r|}
\hline 0.103 \\
\hline 0.102 \\
\hline 0.102 \\
\hline 0.104 \\
\hline 0.1070 \\
\hline
\end{tabular}

Not compensating for water vapor

\begin{tabular}{|l|}
\hline 0.106 \\
\hline 0.106 \\
\hline 0.104 \\
\hline 0.104 \\
\hline 0.104 \\
\hline $\mathbf{0 . 1 0 4}=$ avg \\
$\mathbf{1 . 0 4 2}=$ avg/standard
\end{tabular}

Standards Used:

\begin{tabular}{|c|c|c|c|c|}
\hline Standards Used: & & \multicolumn{2}{|c|}{ Expiration date: } & \\
\hline Scott Specialty Gas & 0.1 ppm SF6 in air, CLM002314 & \multicolumn{2}{|c|}{$3 / 3 / 2012$} & \\
\hline Scott Specialty Gas & 5.01 ppm SF6 in air, CAL011887 & \multicolumn{2}{|c|}{$3 / 3 / 2013$} & \\
\hline \multicolumn{2}{|c|}{ Fisher Scientific SN 90936818} & \multicolumn{2}{|c|}{$10 / 20 / 2011$} & \\
\hline $\begin{array}{l}\text { Entries made by: } \\
\text { Signature/date }\end{array}$ & $\begin{array}{l}\text { John Glissmeyer } \\
\text { On File with Original }\end{array}$ & \multicolumn{3}{|c|}{ 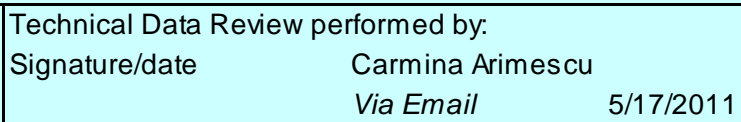 } \\
\hline
\end{tabular}

B\&K

Calibration

readings: (ppm)

Compensating for water vapor

\begin{tabular}{|r|}
\hline 5.09 \\
\hline 5.09 \\
\hline 5.09 \\
\hline 5.08 \\
\hline 5.09 \\
\hline
\end{tabular}

Not compensating for water vapor

\begin{tabular}{|r|}
\hline 5.11 \\
\hline 5.10 \\
\hline 5.09 \\
\hline 5.09 \\
\hline 5.08 \\
\hline $\mathbf{5 . 0 9}=$ avg \\
$\mathbf{1 . 0 1 6}=$ avg/standard
\end{tabular}

Expiration date:

Cylinder CAL011887

start $P=1750$ psi

end $P=1650$ psi 



\section{DISTRIBUTION}

No. of

Copies

\section{OFFSITE}

6 Tim Solle

Idaho National Laboratory

Materials \& Fuels Complex

Scoville, ID 83415

(208) 533-7544

[send FedEx/UPS]

\section{ONSITE}

8 Pacific Northwest National Laboratory

\begin{tabular}{ll}
\hline J.A. Glissmeyer (5) & K9-30 \\
J.E. Flaherty (1) & K9-30 \\
Information Release (2) & P8-55
\end{tabular}

Distr. 1 